\title{
Changing the Usual Interpretation of the Structure and Ground State of Cu2+-Layered Perovskites
}

Aramburu, J. A.; García-Fernández, P.; Mathiesen, N. R.; García-Lastra, J. M.; Moreno, M.

Published in:

Journal of Physical Chemistry C

Link to article, DOI:

10.1021/acs.jpcc.8b00608

Publication date:

2018

Document Version

Peer reviewed version

Link back to DTU Orbit

Citation (APA):

Aramburu, J. A., García-Fernández, P., Mathiesen, N. R., GarcíąLastra, J. M., \& Moreno, M. (2018). Changing the Usual Interpretation of the Structure and Ground State of $\mathrm{Cu}^{2+}$-Layered Perovskites. Journal of Physical Chemistry C, 122(9), 5071-5082. https://doi.org/10.1021/acs.jpcc.8b00608

\section{General rights}

Copyright and moral rights for the publications made accessible in the public portal are retained by the authors and/or other copyright owners and it is a condition of accessing publications that users recognise and abide by the legal requirements associated with these rights.

- Users may download and print one copy of any publication from the public portal for the purpose of private study or research.

- You may not further distribute the material or use it for any profit-making activity or commercial gain

- You may freely distribute the URL identifying the publication in the public portal 


\title{
Changing the Usual Interpretation of the Structure and Ground State of $\mathrm{Cu}^{2+}$ Layered Perovskites
}

\author{
J.A. Aramburu*,1, P. García-Fernández¹, N. R. Mathiesen², J. M. Garcia-Lastra ${ }^{2}$, M. \\ Moreno ${ }^{1}$ \\ ${ }^{1}$ Departamento de Ciencias de la Tierra y Física de la Materia Condensada, Universidad \\ de Cantabria, Avenida de los Castros s/n, 39005 Santander, Spain \\ ${ }^{2}$ Department of Energy Conversion and Storage, Technical University of Denmark. \\ Fysikvej 309, 2800 Kgs. Lyngby, Denmark
}

\begin{abstract}
Intense research on hybrid organic-inorganic layered copper perovskites are currently being carried out. Many interesting properties of these materials rest on the strong correlation between electronic structure and local geometry. As up to now no reliable information on the pressure dependence of $\mathrm{Cu}^{2+}-\mathrm{X}^{-}$distances $(\mathrm{X}=\mathrm{Cl}, \mathrm{F})$ has been reported, we have derived them form first-principles calculations on several representative hybrid and inorganic $\mathrm{Cu}^{2+}$ layered compounds. As a salient feature, we find that in all cases the out-of-plane $\mathrm{Cu}^{2+} \mathrm{X}^{-}$distance is nearly insensitive to pressure, contrary to what is found for the short and long in-plane distances. These results thus disprove the widely assumed idea that the local structure arises from a Jahn-Teller effect involving a principal axis in the layer plane. By contrast, the present work demonstrates that the ground state and the local geometry are governed by two main factors. On one hand, the axial internal electric field due to the rest of lattice ions, which favors placing the hole of the $\mathrm{CuX}_{6}{ }^{4-}$ unit in the $3 z^{2}-r^{2}$ level. On the other hand, the existence of an additional orthorhombic instability in the layer plane that nevertheless preserves the dominant $3 z^{2}-r^{2}$ character, in agreement with experimental data of pure and doped $\mathrm{Cu}^{2+}$ layered compounds. This instability is favored in pure compounds by a cooperative mechanism that is also discussed. The present calculations on these systems under pressure show that a slightly elongated $\mathrm{CuX}_{6}{ }^{4-}$ unit can also have the hole in the axial $3 z^{2}-r^{2}$ level, an unexpected situation that can only be explained with the introduction of the often ignored internal electric field.
\end{abstract}




\section{INTRODUCTION}

The search of new and improved functional materials has experienced during the last years a big development with the synthesis of many families of organic-inorganic compounds. These hybrid materials combine the useful electronic properties coming from the inorganic part with the structural versatility of organic molecules giving rise to attractive physico-chemical properties, going far beyond the sum of the properties of its constituent parts ${ }^{1-8}$.

In many hybrid compounds, the inorganic component forms layers separated by the organic elements, controlling the dimensionality of the magnetic and electric behavior in the former layer. In recent years, a great deal of investigation has been focused on layered $R \mathrm{CuX}_{4}$ compounds, where $R$ is an organic group and $\mathrm{X}$ a halogen. Indeed, very promising results have been obtained with this kind of compounds in the realm of lightemitting diodes ${ }^{8}$, solar cells $\mathrm{s}^{8,9}$, multiferroic materials ${ }^{10-12}$, cathode materials for $\mathrm{Li}^{+}$-ion batteries $^{13}$ or systems displaying huge piezochromism and thermochromism ${ }^{14-16}$.

Fig. 1 depicts the experimental crystal structure of $\left(\mathrm{CH}_{3} \mathrm{NH}_{3}\right)_{2} \mathrm{CuCl}_{4}$, a typical example of these copper layered hybrid compounds ${ }^{17}$, belonging to the monoclinic $P 2_{1} / c$ standard space group. It involves staggered layers of corner-sharing $\mathrm{CuCl}_{6}{ }^{4-}$ octahedra interleaved by alkylammonium cations. According to X-ray diffraction data at $T=100 \mathrm{~K}^{17}$ there are two ligands placed along the local $\mathrm{Z}$ axis of the $\mathrm{CuCl}_{6}{ }^{4-}$ unit, which forms a small angle of $7^{\circ}$ with the $L$ vector perpendicular to the layer plane (Fig. 1). The other four ligands are lying in $\mathrm{X}$ and $\mathrm{Y}$ directions nearly contained in the layer plane. The $\mathrm{Cu}^{2+}-\mathrm{Cl}^{-}$distance along $Z\left(R_{Z}=2.312 \AA\right)$ is very close to short metal-ligand distance in the in-plane $X$ direction, $R_{S}$ $=2.287 \AA$, but much smaller than the long one in $\mathrm{Y}$ direction, $\mathrm{R}_{\mathrm{L}}=2.902 \AA$ (Table 1). $\mathrm{A}$ nearly identical pattern is encountered for other members of the $\left(\mathrm{C}_{n} \mathrm{H}_{2 n+1} \mathrm{NH}_{3}\right)_{2} \mathrm{CuCl}_{4}$ family (Table 2) ${ }^{18,19}$. This situation is thus seemingly similar to that found for $\mathrm{Cu}^{2+}$-doped cubic lattices, like $\mathrm{KZnF}_{3}{ }^{20-23}$ or $\mathrm{NaCl}^{25-27}$, where the ligand octahedron is elongated and the local symmetry tetragonal as a result of a static Jahn-Teller effect (JTE) ${ }^{28,29}$. For this simple reason, it has systematically been accepted ${ }^{9-16,30,31}$ that the JTE is behind the local distortion around the metal cation in $\mathrm{RCuCl}_{4}$ compounds. A similar situation holds for purely inorganic materials displaying a layer structure, such as $\mathrm{K}_{2} \mathrm{CuF}_{4}{ }^{32-34}, \mathrm{Rb}_{2} \mathrm{CuCl}_{4}{ }^{35}$, $\mathrm{Cs}_{2} \mathrm{AgF}_{4}{ }^{36}$ or $\mathrm{Na}_{3} \mathrm{MnF}_{6}{ }^{37,38}$. Under that assumption, the principal axis of the distorted octahedron would however lie in the layer plane, a circumstance which is certainly surprising in view of the axial character displayed by layered compounds.

This work is aimed at clarifying both the origin of the local structure of $\mathrm{CuX}_{6}{ }^{4-}(\mathrm{X}=\mathrm{Cl}, \mathrm{F})$ units in layered copper lattices and the nature of the ground state of that complex as it is a necessary condition for a proper understanding of their associated properties, such as the huge piezochromism observed in some $R C u X_{4}$ compounds ${ }^{14-16}$. A particular attention is paid to explore the influence of an applied pressure on $\mathrm{Cu}^{2+}-\mathrm{X}$ - distances ( $\mathrm{X}$ $=\mathrm{Cl}, \mathrm{F}$ ) as it is a crucial test to assess the reliability of the JTE assumption. Indeed, if the local structure around copper is actually due to a JTE the pressure dependence of the short in-plane distance, $R_{S}$, and the out-of-plane distance, $R_{z}$, should be the same. As there are no reliable experimental data on this matter $30,31,35,39$, we have carried out in 
this work first-principles calculations proving that, for all the explored systems, the Rs distance is much more sensitive to pressure than $R_{z}$, such as it is shown in the section of the discussion of results. For this reason, we have later sought to understand the mechanisms that explain the observed local structure and the electronic ground state of the $\mathrm{CuX}_{6}{ }^{4-}(\mathrm{X}=\mathrm{Cl}, \mathrm{F})$ complex. For achieving this goal, we have found that theoretical calculations and available experimental data on $\mathrm{Cu}^{2+}$-doped $\left(\mathrm{CH}_{3} \mathrm{NH}_{3}\right)_{2} \mathrm{CdCl}_{4}{ }^{40,41}$ together with previous results on the orbital ordering in $\mathrm{K}_{2} \mathrm{CuF}_{4}{ }^{42}$ play a key role for clarifying this relevant question. As a salient feature, it is shown in this work that the properties of layered copper compounds are influenced by two main factors often ignored: (1) the axial internal electric field felt by electrons localized in the $\mathrm{CuXX}_{6}{ }^{4-}$ unit, and (2) an orthorhombic instability taking place in the layer plane which is favored in pure compounds by a cooperative mechanism.

\section{COMPUTATIONAL METHODS}

Periodic geometry optimizations on $\left(\mathrm{CH}_{3} \mathrm{NH}_{3}\right)_{2} \mathrm{CdCl}_{4},\left(\mathrm{CH}_{3} \mathrm{NH}_{3}\right)_{2} \mathrm{CuCl}_{4}, \mathrm{~K}_{2} \mathrm{CuF}_{4}$ and $\mathrm{Rb}_{2} \mathrm{CuCl}_{4}$ were firstly performed under the framework of the Density Functional Theory (DFT) by means of the CRYSTAL14 code ${ }^{43}$. In this code, the Bloch wavefunctions are represented by a linear combination of Gaussian basis functions centered at the atomic positions. All ions have been described by means of basis-sets taken directly from CRYSTAL's webpage ${ }^{43}$. In particular, we have used the all-electron triple- $\zeta$ plus polarization (TZP) basis recently developed for Peitinger et al. ${ }^{44}$. We have also used the B1WC hybrid exchange-correlation functional (including 16\% of Hartree-Fock exchange) that has shown to be able to reproduce with great accuracy the geometry and properties of a large number of both pure and doped crystals ${ }^{45}$. Similar results have been found using other basis sets and the PW1PW hybrid functional ${ }^{46}$ (including $20 \%$ of HartreeFock exchange).

All optimized geometries agree with the experimental values within $2 \%$ error, except in the case of $\left(\mathrm{CH}_{3} \mathrm{NH}_{3}\right)_{2} \mathrm{CuCl}_{4}$, where the lattice parameters and metal-ligand distances are within $5 \%$. This discrepancy is due to the problems inherent to describe a system with relevant van der Walls interactions by means of localized basis sets generated for a general purpose. For this reason, we performed additional calculations with the VASP code $\mathrm{e}^{4-50}$ that uses a combination of localized orbitals and plane-wave expansions (PAW) as basis sets ${ }^{51-53}$. We used the HSEsol hybrid functional (with $20 \%$ Hartee-Fock exchange) which has been shown to yield accurate lattice constants for solids ${ }^{54}$. A $500 \mathrm{eV}$ cutoff energy was used, and a Monkhorst-Pack ${ }^{55}$ of $2 \times 2 \times 2$ and $3 \times 1 \times 3$ were chosen as k-point mesh for the $\left(\mathrm{CH}_{3} \mathrm{NH}_{3}\right)_{2} \mathrm{CuCl}_{4}$ and $\left(\mathrm{CH}_{3} \mathrm{NH}_{3}\right)_{2} \mathrm{CdCl}_{4}$ systems, respectively. Geometries were relaxed until forces were lower than $0.02 \AA / \mathrm{eV}$.

Calculations on $\mathrm{Cu}^{2+}$-doped $\left(\mathrm{CH}_{3} \mathrm{NH}_{3}\right)_{2} \mathrm{CdCl}_{4}$, where $\mathrm{Cu}^{2+}$ impurity enters replacing a $\mathrm{Cd}^{2+}$ ion of the lattice, were performed both with CRYSTAL14 and VASP codes, using a periodic conventional cell containing 84 ions with the lattice parameters fixed at the experimental values. The results were very similar with both codes. 
In order to explore whether the orthorhombic instability also appears in mixed $\mathrm{K}_{2} \mathrm{Cu}_{x} \mathrm{Zn}_{1}$ ${ }_{x} F_{4}$ crystals $(0<x \leq 1)$ we have performed calculations in the tetragonal $14 / \mathrm{mmm}$ espace group and using an in-plane doubled supercell of size $\sqrt{ } 2 \times \sqrt{ } 2 \times 1$.

For each crystal structure considered in this work we have calculated the electrostatic potential $V_{R}(r)$ felt by the electrons localized in the $\mathrm{MX}_{6}{ }^{4-}\left(\mathrm{M}=\mathrm{Cu}^{2+}, \mathrm{Cd}^{2+} ; \mathrm{X}=\mathrm{F}^{-}, \mathrm{Cl}^{-}\right)$ complex due to all lattice ions lying outside. Although often ignored, the $V_{R}(r)$ potential is the actual responsible for the ground state of $\mathrm{K}_{2} \mathrm{ZnF}_{4}: \mathrm{Cu}^{2+}{ }^{56}$ or the different color displayed by ruby, emerald or alexandrite gemstones ${ }^{57}$. Calculations have been performed by means of the Ewald method ${ }^{58,59}$, following the procedure described in ${ }^{57}$. In these calculations we have used the ionic charges obtained in the first-principles geometry optimizations.

The present work is mainly focused on the local structure and ground state of $\mathrm{CuX}_{6}{ }^{4-}(\mathrm{X}$ $=\mathrm{Cl}, \mathrm{F}$ ) complexes in copper layered compounds. Although we do not discuss in detail the problem of exchange interaction among complexes, we have verified that the local structure and atomic orbital contributions are essentially independent on the magnetic order. So, the calculated $\mathrm{Cu}^{2+}-\mathrm{F}^{-}$distances in $\mathrm{K}_{2} \mathrm{CuF}_{4}$ vary relatively by less than $5 \cdot 10^{-4}$ when changing from a ferromagnetic to an antiferromagnetic structure.

\section{RESULTS AND DISCUSSION}

\subsection{Equilibrium geometry at zero pressure}

In a first step we have calculated the equilibrium geometry of the hybrid perovskite $\left(\mathrm{CH}_{3} \mathrm{NH}_{3}\right)_{2} \mathrm{CuCl}_{4}$ (monoclinic $\mathrm{P}_{2} / \mathrm{C}$ space group, Fig. 1$)^{17}$, and also that for inorganic layered lattices $\mathrm{K}_{2} \mathrm{CuF}_{4}$ (Fig. 2) ${ }^{32}$ and $\mathrm{Rb}_{2} \mathrm{CuCl}_{4}$ (Fig. 3) ${ }^{60}$, both of them belonging to the orthorhombic Cmca standard space group. Results are displayed on Table 1.

Additional calculations have also been performed on $\left(\mathrm{CH}_{3} \mathrm{NH}_{3}\right)_{2} \mathrm{CdCl}_{4} 61,62$ as it is a necessary step for a further study of $\left(\mathrm{CH}_{3} \mathrm{NH}_{3}\right)_{2} \mathrm{CdCl}_{4}: \mathrm{Cu}^{2+}$, where $\mathrm{Cu}^{2+}$ enters as impurity, which is developed in sections 3.3 and 3.4. It is worth noting that, although $\left(\mathrm{CH}_{3} \mathrm{NH}_{3}\right)_{2} \mathrm{CdCl}_{4}$ belongs to the orthorhombic $\mathrm{Cmca}$ group, the local geometry around $\mathrm{Cd}^{2+}$ is tetragonal, that is $\mathrm{R}_{\mathrm{S}}=\mathrm{R}_{\mathrm{L}}$ (Table 1 ).

The calculated lattice constants and metal-ligand distances for these compounds are collected In Table 1 and compared to experimental findings. We can see that simulations capture the geometry of these systems with high accuracy, with errors in the predicted distances below $1 \%$ in most cases. The only significant discrepancy occurs in $\left(\mathrm{CH}_{3} \mathrm{NH}_{3}\right)_{2} \mathrm{CuCl}_{4}$ were distances obtained with the CRYSTAL code diverge to up to $5 \%$. The main problem here resides in the use of localized basis sets that do not capture with sufficient accuracy the van der Waals interactions due to the organic part of the lattice. We find that, either using the more detailed Plane-Augmented-Wave (PAW) basis-sets in VASP code or when fixing the lattice constants to the experimental ones in CRYSTAL code, we obtain very satisfactory results on metal-ligand distances (Table 1). 
It is worth noting in Table 1 that, at variance with the local tetragonal geometry for $\left(\mathrm{CH}_{3} \mathrm{NH}_{3}\right)_{2} \mathrm{CdCl}_{4}$, in the three pure copper compounds the in-plane $\mathrm{Cu}^{2+}-\mathrm{X}^{-}$distance $(\mathrm{X}=$ $\mathrm{Cl}, \mathrm{F}), \mathrm{R}_{\mathrm{L}}$, is certainly longer ( 0.3-0.6 $\AA$ ) than $\mathrm{R}_{S}$ and $\mathrm{R}_{\mathrm{Z}}$. Interestingly, the values of $\mathrm{R}_{S}$ and $R_{z}$ distances are not equal although they are very close, the difference $R_{z}-R_{S}=0.03$ $\AA$ and $0.05 \AA$ for $\left(\mathrm{CH}_{3} \mathrm{NH}_{3}\right)_{2} \mathrm{CuCl}_{4}$ and $\mathrm{Rb}_{2} \mathrm{CuCl}_{4}$, respectively. These facts already cast some doubts on the JTE assumption as the two $\mathrm{Cu}^{2+}-\mathrm{Cl}^{-}$distances in the plane perpendicular to the expected principal axis should be equal. The reliability of that assumption is examined in detail exploring the pressure dependence of $R_{S}, R_{L}$ and $R_{Z}$ distances in the next section.

\subsection{Influence of a hydrostatic pressure on $\mathrm{Cu}^{2+}-\mathrm{X}^{-}$distances of layered compounds}

Several studies have shown the high sensitivity of the properties, like optical absorption ${ }^{14-16}$, to the modification of the structure as, for example, when applying pressure. However, a precise determination of the pressure dependence of three $\mathrm{Cu}^{2+}$ $\mathrm{X}$ - distances is not a simple experimental task. For instance the $\mathrm{X}$-ray diffraction data on powder samples of $\left(\mathrm{C}_{2} \mathrm{H}_{5} \mathrm{NH}_{3}\right)_{2} \mathrm{CuCl}_{4}$ are not sensitive enough to reveal the pressure dependence of $\mathrm{R}_{\mathrm{S}}$ and $\mathrm{R}_{\mathrm{Z}}$ distances ${ }^{31}$. On the other hand, in $\mathrm{Rb}_{2} \mathrm{CuCl}_{4}$ the analysis of data has been carried out under the assumption $\mathrm{R}_{\mathrm{s}}=\mathrm{R}_{\mathrm{z}}$ for every applied pressure.

Seeking to clarify this key issue we have explored, in a first step, the changes induced by an external pressure upon the lattice parameters and $\mathrm{Cu}^{2+}-\mathrm{Cl}^{-}$distances of $\left(\mathrm{CH}_{3} \mathrm{NH}_{3}\right)_{2} \mathrm{CuCl}_{4}$ keeping the $P 2_{1} / \mathrm{C}$ space group. It is worth noting that under hydrostatic conditions all surfaces of a given sample are subject to the same pressure although the strain generated in the system is not isotropic for non-cubic crystals. Results obtained through ab initio calculations with the VASP code are displayed in Fig. 4 and Table 2. As a salient feature they show that the out-of-plane distance, $R_{z}$, is practically unaffected by the application of pressure as it increases by only $0.5 \%$ from zero pressure to $P=20$ $\mathrm{GPa}$. By contrast, much bigger variations are found for the short in-plane distance along the $\mathrm{X}$ axis, $\mathrm{Rs}$, as it is reduced by $7.2 \%$ in the same range of pressure. This big difference is thus against the common idea of a JTE as responsible for the local structure in $\left(\mathrm{CH}_{3} \mathrm{NH}_{3}\right)_{2} \mathrm{CuCl}_{4}$. As it could be expected, the biggest effect is found for the longest $\mathrm{Cu}^{2+}$ $\mathrm{Cl}^{-}$distance, $\mathrm{R}_{\mathrm{L}}$, that is reduced by $0.69 \AA$ (23.7\%) under a hydrostatic pressure of $20 \mathrm{GPa}$. This fact is consistent with experimental data on hybrid $\mathrm{RCuCl}_{4}$ compounds showing that the longest $\mathrm{Cu}^{2+}-\mathrm{Cl}^{-}$distance is also the most sensitive to the change of the $R$ group and the associated chemical pressure (Table 3).

Interestingly, we find that when the pressure P > $15 \mathrm{GPa}$ the out-of-plane $\mathrm{Cu}^{2+}-\mathrm{Cl}^{-}$ distance, $R_{z}$, becomes the longest metal-ligand distance while the in-plane ones, $R_{s}$ and $\mathrm{R}_{\mathrm{L}}$, differ only by less than $7 \%$. In other words, in that situation the system becomes quasi-tetragonal with the long bond of the octahedron aligned with the axis perpendicular to the $\mathrm{Cu}^{2+}$-layers. In order to check that the structures obtained in our calculations corresponded with the most stable situation we carried out vibrational frequency calculations for the high-symmetry configuration at each pressure. We find that only the modes associated to the orthorhombic distortions at $M_{0}$ and $T_{0}$ lead to 
instabilities corroborating that the structures previously reported are, energetically, the most stable.

To our knowledge there are no X-ray data for $\left(\mathrm{CH}_{3} \mathrm{NH}_{3}\right)_{2} \mathrm{CuCl}_{4}$ under pressure. By contrast, resonant $\mathrm{x}$-ray scattering measurements on powder samples of $\left(\mathrm{C}_{2} \mathrm{H}_{5} \mathrm{NH}_{3}\right)_{2} \mathrm{CuCl}_{4}$ under pressures up to $4 \mathrm{GPa}$ have been reported by Ohwada et al. ${ }^{31}$. However, due to the low experimental resolution, they were unable to detect the changes due to pressure on $R_{L}$ and $R_{S}$ distances although they found that $R_{L}$ is highly sensitive. Indeed, although the dependence of $R_{L}$ with pressure is not linear, this quantity decreases by $\sim 0.4 \AA$ due to an applied pressure of $4 \mathrm{GPa}$.

The calculated pressure dependence of three metal-ligand distances in $\mathrm{K}_{2} \mathrm{CuF}_{4}$, portrayed in Fig. 5, shows a similar behavior to that found for $\left(\mathrm{CH}_{3} \mathrm{NH}_{3}\right)_{2} \mathrm{CuCl}_{4}$ (Fig. 4). For instance, a pressure of $8.7 \mathrm{GPa}$ is found to reduce the value of $\mathrm{R}_{s}$ by $2.5 \%$, while $\mathrm{R}_{\mathrm{Z}}$ experiences no change. Again, the biggest variation corresponds to the long $\mathrm{Cu}^{2+}-\mathrm{F}^{-}$ distance, $R_{L}$, that is reduced by $7 \%$.

Interestingly, the results of Fig. 5 also show that pressure tends to reduce the value of $\mathrm{R}_{\mathrm{L}}-\mathrm{R}_{\mathrm{S}}$ thus recovering a nearly elongated tetragonal symmetry of the $\mathrm{CuF}_{6}{ }^{4-}$ unit with $\mathrm{Z}$ as principal axis. For instance, for a hydrostatic pressure $\mathrm{P}=60 \mathrm{GPa}$ and an orthorhombic Cmca space group the calculated $\mathrm{Cu}^{2+}{ }_{-} \mathrm{F}^{-}$distances are $\mathrm{R}_{\mathrm{S}}=1.72 \AA \mathrm{R}_{\mathrm{L}}=1.78 \AA$ and $\mathrm{R}_{\mathrm{Z}}=$ $1.94 \AA ̊$.

It is worth noting that such distances obtained for $\mathrm{P}=60 \mathrm{GPa}$ describe a slightly elongated $\mathrm{CuF}_{6}{ }^{4-}$ complex but with an unpaired electron residing in a $\sim 3 z^{2}-r^{2}$ orbital as it is well found in the calculations. This situation cannot happen for a $\mathrm{Cu}^{2+}$ ion in a cubic lattice where a subsequent JTE necessarily places such an electron in the $\sim x^{2}-y^{2}$ orbital if the equilibrium geometry is elongated. As it will be discussed in detail in section 3.4 this behavior is due to the presence of a very anisotropic electrostatic potential, $V_{R}(r)$ created by the rest of lattice ions on the electrons localized in the $\mathrm{CuF}_{6}{ }^{4-}$ complex. This internal electric field makes possible that the hole can still be in the $\sim 3 z^{2}-r^{2}$ orbital despite the local geometry is slightly elongated. Accordingly, we have verified that the calculated gap between $x^{2}-y^{2}$ and $3 z^{2}-r^{2}$ levels when $P=60 \mathrm{GPa}$ is reduced by $50 \%$ when compared to that at ambient pressure for the $14 / \mathrm{mmm}$ structure but $3 z^{2}-r^{2}$ is still the highest level. The existence of this surprising situation for non-JTE systems was previously discussed ${ }^{63}$.

Calculations carried out on $\mathrm{Rb}_{2} \mathrm{CuCl}_{4}$ under pressure (Fig. 5) provide a similar pattern to those for $\left(\mathrm{CH}_{3} \mathrm{NH}_{3}\right)_{2} \mathrm{CuCl}_{4}$ and $\mathrm{K}_{2} \mathrm{CuF}_{4}$. Indeed, for a pressure of $10 \mathrm{GPa} \mathrm{R}_{\mathrm{L}}$ is reduced by $0.36 \AA$ ( $13 \%)$ while $R_{S}$ by $0.10 \AA$ ( $\left.4.4 \%\right)$ and again $R_{Z}$ is found to be much less sensitive to pressure. These values are thus comparable to those found for $\left(\mathrm{CH}_{3} \mathrm{NH}_{3}\right)_{2} \mathrm{CuCl}_{4}$ (Fig. 4 and Table 2). Moreover, the data conveyed in Fig. 5 for $\mathrm{Rb}_{2} \mathrm{CuCl}_{4}$ indicate that for a pressure around $20 \mathrm{GPa} \mathrm{R}_{\mathrm{L}}$ and $\mathrm{R}_{\mathrm{S}}$ become very close. In such a case, the local geometry would practically correspond to an elongated octahedron in the out-of-plane direction but with a hole located in $\sim 3 z^{2}-r^{2}$ as it has also been found for $\mathrm{K}_{2} \mathrm{CuF}_{4}$. 
Concerning experimental data, Ishizuka et al. ${ }^{39}$ have explored the pressure dependence of lattice parameters on $\mathrm{K}_{2} \mathrm{CuF}_{4}$ but not of three $\mathrm{Cu}^{2+}-\mathrm{F}^{-}$distances. In the case of $\mathrm{Rb}_{2} \mathrm{CuCl}_{4}, \mathrm{X}$-ray Difraction (XRD) and Extended X-Ray Absorption Fine Structure (EXAFS) measurements have been carried out under pressures up to $15 \mathrm{GPa}^{35}$. From XRD data it can be concluded that the long $\mathrm{Cu}^{2+}-\mathrm{Cl}^{-}$distance, $\mathrm{R}$, is reduced by $\sim 0.30 \AA$ on passing from $P=0$ to $P=10 \mathrm{GPa}$, in reasonable agreement with present calculations for $\mathrm{Rb}_{2} \mathrm{CuCl}_{4}$. Unfortunately, for the analysis of these experimental EXAFS data it was assumed ${ }^{35}$ that the local geometry for $\mathrm{Rb}_{2} \mathrm{CuCl}_{4}$ is the result of an elongated JTE, and thus $\mathrm{RS}_{\mathrm{S}}=\mathrm{Rz}_{\mathrm{z}}$ for every applied pressure. This artificial constraint when analyzing the experimental data prevents extracting the significant differences between $R_{S}$ and $R_{Z}$ reported in this work. Moreover, from the analysis of EXAFS data it is concluded that $\Delta R_{L} / \Delta P=-0.012 \AA / G P a$, a quantity that is nearly three times smaller than that derived from XRD and the present calculations. Although this discrepancy has been ascribed to the existence of a significant tilting in the $\mathrm{CuCl}_{6}{ }^{4-}$ octahedral ${ }^{35}$, no tilting is found in the present ab initio calculations in the $\mathrm{P}=0-20 \mathrm{GPa}$ range. Such a discrepancy can arise from the reduced number of detected EXAFS oscillations, such as it is recognized in the experimental work ${ }^{35}$.

The present results thus prove that the calculated pressure dependence for several layered copper compounds cannot be explained under the usual assumption of a JTE ${ }^{9-}$ 16,30-35. For clarifying the actual origin of the local structure in these layered systems and the nature of the electronic ground state an insight on $\left(\mathrm{CH}_{3} \mathrm{NH}_{3}\right)_{2} \mathrm{CdCl}_{4}: \mathrm{Cu}^{2+}$, where $\mathrm{Cu}^{2+}$ enters as impurity ${ }^{40}$, sheds light on this relevant matter. A study on that system is carried out in the next section.

\subsection{Calculated equilibrium geometry and ground state for $\left(\mathrm{CH}_{3} \mathrm{NH}_{3}\right)_{2} \mathrm{CdCl}_{4}: \mathrm{Cu}^{2+}$ : Analysis of experimental data}

As shown in Table 1 and Fig. 6 the local geometry around $\mathrm{Cd}^{2+}$ in $\left(\mathrm{CH}_{3} \mathrm{NH}_{3}\right)_{2} \mathrm{CdCl}_{4}$ is tetragonal $\left(R_{S}=R_{L}\right)$ displaying a slightly compressed octahedron $\left(R_{Z}=2.54 \AA\right.$, $R_{S}=2.64$ $\AA)$. The calculated $\mathrm{Cd}^{2+}-\mathrm{Cl}^{-}$distances for this pure compound coincide within $1 \%$ with experimental values (Table1). For this reason, we have calculated, as a first step, the equilibrium distances in $\left(\mathrm{CH}_{3} \mathrm{NH}_{3}\right)_{2} \mathrm{CdCl}_{4}: \mathrm{Cu}^{2+}$ assuming the same $\mathrm{D}_{4 \mathrm{~h}}$ local symmetry around the impurity, and the results are displayed in Table 4.

When the optimization is constrained to the $D_{4 h}$ local symmetry by the condition $R_{S}=R_{L}$ the equilibrium geometry of the $\mathrm{CuCl}_{6}{ }^{4-}$ unit is found to correspond to a compressed octahedron whose principal axis is the local $Z$ axis, that forms a small angle of 70 with the crystal $\boldsymbol{b}$ axis. In that situation, the unpaired electron is lying in the $a_{1 \mathrm{~g}} \sim 3 z^{2}-r^{2}$ molecular orbital of the complex. Nevertheless, as shown in Table 4 , the quantity $R_{S}-R_{z}$, reflecting the tetragonality of the complex, is three times bigger than that for the $\mathrm{Cd}^{2+}$ octahedron (Table 1). This situation, somewhat similar to that found for the $\mathrm{CuF}_{6}{ }^{4-}$ unit in $\mathrm{Ba}_{2} \mathrm{ZnF}_{6}: \mathrm{Cu}^{2+23}$, points out that in $\left(\mathrm{CH}_{3} \mathrm{NH}_{3}\right)_{2} \mathrm{CdCl}_{4}: \mathrm{Cu}^{2+}$ the tetragonality around the open shell cation, $\mathrm{Cu}^{2+}$, is enhanced with respect to that found for the $\mathrm{CdCl}_{6}{ }^{4-}$ unit. As recently proved for the layered systems $\mathrm{Ba}_{2} \mathrm{ZnF}_{6}: \mathrm{Cu}^{2+}{ }^{23}$ or $\mathrm{K}_{2} \mathrm{ZnF}_{4}: \mathrm{Cu}^{2+}{ }^{26}$, this effect is greatly due to the anisotropic internal electric field, $E_{R}(\mathbf{r})$, generated by the electrostatic 
potential, $V_{R}(\mathbf{r})$, felt by the electrons localized in the complex due to all lattice ions lying outside. It is worth noting that $\mathrm{V}_{\mathrm{R}}(\mathbf{r})$ can induce shifts up to $\sim 1 \mathrm{eV}$ on optical transitions ${ }^{64}$ and is responsible for the different color displayed by $\mathrm{Cr}^{3+}$-based gemstones ${ }^{57}$.

The shape of the $\mathrm{V}_{\mathrm{R}}(\mathbf{r})$ potential for $\left(\mathrm{CH}_{3} \mathrm{NH}_{3}\right)_{2} \mathrm{CdCl}_{4}: \mathrm{Cu}^{2+}$ is depicted in Fig. 6 . It can be remarked that the anisotropic $V_{R}(r)$ potential increases the energy of an electronic density along the $Z$ axis with respect to that located in the layer plane. This fact thus creates a gap between $b_{1 g} \sim x^{2}-y^{2}$ and $a_{1 g} \sim 3 z^{2}-r^{2}$ molecular orbitals even if $R_{S}=R_{L}=R_{z}$, forcing the hole to be placed in the $\mathrm{a}_{1 \mathrm{~g}} \sim 3 z^{2}-r^{2}$ single orbital ${ }^{56,22}$. The lack of orbital degeneracy when the $\mathrm{CuCl}_{6}{ }^{4-}$ unit in $\left(\mathrm{CH}_{3} \mathrm{NH}_{3}\right)_{2} \mathrm{CdCl}_{4}$ is perfectly octahedral underlines the absence of a JTE in this system such as it happens for the $\mathrm{CuF}_{6}{ }^{4-}$ complex formed in $\mathrm{Cu}^{2+}$-doped the layered $\mathrm{K}_{2} \mathrm{ZnF}_{4}$ or $\mathrm{Ba}_{2} \mathrm{ZnF}_{6}$ compounds ${ }^{23,56}$. Moreover, a hole placed in a $\sim 3 z^{2}-r^{2}$ orbital with a mainly axial character favors the reduction of the axial distance ${ }^{56}$ and thus a compressed local conformation with $\mathrm{Rz}_{z}=2.27 \AA$. This reasoning thus explains, albeit qualitatively, why the equilibrium geometry of the $\mathrm{CuCl}_{6}{ }^{4-}$ unit in $\left(\mathrm{CH}_{3} \mathrm{NH}_{3}\right)_{2} \mathrm{CdCl}_{4}$ would correspond to a compressed octahedron assuming a local tetragonal symmetry (Table 4). It is worth noting that in such a case the equatorial metal-ligand distance, $\mathrm{R}_{\mathrm{s}}=$ $\mathrm{R}_{\mathrm{L}}=2.56 \AA$, would be around $0.20 \AA$ higher than that for an elongated $\mathrm{CuCl}_{6}{ }^{4-}$ unit ${ }^{65}$.

Nevertheless, as it is shown on Table 4, the present calculations on $\left(\mathrm{CH}_{3} \mathrm{NH}_{3}\right)_{2} \mathrm{CdCl}_{4}: \mathrm{Cu}^{2+}$ strongly support that the tetragonal geometry around $\mathrm{Cu}^{2+}$ is unstable thus leading to a local orthorhombic symmetry involving two different values for the in-plane $\mathrm{Cu}^{2+}-\mathrm{Cl}^{-}$ distances, $R_{S}$ and $R_{L}$. Due to this instability $R_{L}\left(R_{S}\right)$ increases (decreases) by about $0.12 \AA$ on passing from $D_{4 h}$ to a $D_{2 h}$ local symmetry. By contrast, the out-of-plane distance, $R_{z}$, remains practically constant as it only increases by $\sim 1 \%$ in the symmetry lowering process. It should already be noted that the calculated $\mathrm{Rz}$ values for $\left(\mathrm{CH}_{3} \mathrm{NH}_{3}\right)_{2} \mathrm{CdCl}_{4}: \mathrm{Cu}^{2+}$ (Table 4) are only $1.7 \%$ smaller than $\mathrm{R}_{\mathrm{Z}}=2.312 \AA$ measured for the pure compound $\left(\mathrm{CH}_{3} \mathrm{NH}_{3}\right)_{2} \mathrm{CuCl}_{4}$ at $\mathrm{T}=100 \mathrm{~K}$ (Table 1$)^{17}$. Values of $\mathrm{R}_{\mathrm{Z}}$ in the range $2.28 \AA-2.29 \AA$ have been reported for $\left(\mathrm{C}_{n} \mathrm{H}_{2 n+1} \mathrm{NH}_{3}\right)_{2} \mathrm{CuCl}_{4}$ compounds with $n=2,3$ (Table 3) ${ }^{18,19}$.

The existence of this orthorhombic instability implies that the force constant associated with the $B_{1 g}$ local mode becomes negative ${ }^{66}$, a fact which again cannot be associated with a JTE. Indeed, in a static JTE, taking place under an initial cubic symmetry, the force constant is always positive and the distortion arises from an electronic density that exhibits a lower symmetry thus producing a different force on axial and equatorial ligands ${ }^{67,29}$.

Two main consequences are behind the orthorhombic instability derived for $\left(\mathrm{CH}_{3} \mathrm{NH}_{3}\right)_{2} \mathrm{CdCl}_{4}: \mathrm{Cu}^{2+}$. On one hand, the energy for the tetragonal $\mathrm{D}_{4 \mathrm{~h}}$ conformation has to be higher than that for the orthorhombic $D_{2 h}$ local symmetry. Calling $B$ such $a$ difference we have found in our calculations that $B=0.40 \mathrm{eV}$. On the other hand, according to the symmetry of the host lattice there are two equivalent orthorhombic distortions, as shown in Fig. 6. Indeed, the short in-plane distance, $\mathrm{R}_{\mathrm{s}}$, can be either along the $X^{\prime}$ or the $Y^{\prime}$ direction of the host lattice in Fig. 6 . If the transition state between these two distortions corresponds to the tetragonal conformation $\left(R_{S}=R_{L}=2.560 \AA, R_{Z}=2.257\right.$ $\AA$ ) then the barrier between the two equivalent distortions would be $B=0.40 \mathrm{eV}$. 
Bearing the results of calculations in mind let us now analyze the available EPR results on $\left(\mathrm{CH}_{3} \mathrm{NH}_{3}\right)_{2} \mathrm{CdCl}_{4}: \mathrm{Cu}^{2+} 40$. As shown in Fig. 7, the experimental $g$-tensor at $\mathrm{T}=10 \mathrm{~K}$ displays a clear orthorhombic pattern, a fact consistent with the instability derived from the present calculations (Table 4). Indeed there is a clear difference between the two components of the g-tensor corresponding to the layer plane, $g_{X}=2.12$ and $g_{Y}=2.33$, supporting that the in-plane $\mathrm{Cu}^{2+}-\mathrm{Cl}^{-}$distances, $\mathrm{R}_{\mathrm{S}}$ and $\mathrm{R}_{\mathrm{L}}$, are actually different. In this case, the $X$ and $Y$ directions correspond to the short and long in plane directions, respectively. Both $g_{x}-g_{0}$ and $g_{\gamma}-g_{0}$ shifts are larger than $g_{z}-g_{0}=0.05$ thus pointing out a significant difference between the $Z$ direction and the layer plane.

With respect to the temperature dependence of the g-tensor in the $10 \mathrm{~K}-250 \mathrm{~K}$, experimental results (Fig. 7) indicate that $g_{\gamma}$ decreases and $g_{x}$ increases when temperature is raised while gz remains essentially constant. The results of Fig. 7 imply the existence of jumps between the two equivalent positions depicted in Fig. 6 whose frequency increases with temperature. This means that in the time of measurement the short $X$ axis is moving from the $X^{\prime}$ to the $Y^{\prime}$ direction of the host lattice in Fig. 6 . As shown in Fig. 7, no average signal corresponding to $\langle\mathrm{g}\rangle=\left(\mathrm{g}_{\mathrm{X}}+\mathrm{g}_{\mathrm{y}}\right) / 2$ is observed up to $250 \mathrm{~K}$ although such a signal with $\langle\mathrm{g}\rangle=2.24$ has been detected at higher temperatures ${ }^{40}$.

Despite the incoherent dynamical behavior displayed by the experimental g-tensor in Fig. 7 partially reminds that for a static JTE in cubic lattices there are however significant differences. On one hand, in cases like $\mathrm{NaCl}: \mathrm{Cu}^{2+}{ }^{24}, \mathrm{KZnF}_{3}: \mathrm{Cu}^{2+} 20$ or $\mathrm{KCl}: \mathrm{Ag}^{2+25,26}$ there are three and not two equivalent distortions while for $\left(\mathrm{CH}_{3} \mathrm{NH}_{3}\right)_{2} \mathrm{CdCl}_{4}: \mathrm{Cu}^{2+}$ the local $\mathrm{Z}$ axis is fixed in the $10 \mathrm{~K}-250 \mathrm{~K}$ temperature range as shown in Fig. 7. On the other hand, for systems with a static JTE the average signal is observed for temperatures, $T_{t}$, in the range $30 \mathrm{~K}-180 \mathrm{~K}^{23,25-27}$ while for $\left(\mathrm{CH}_{3} \mathrm{NH}_{3}\right)_{2} \mathrm{CdCl}_{4}: \mathrm{Cu}^{2+}$ the average spectrum with $\langle\mathrm{g}\rangle=$ $\left(\mathrm{g}_{\mathrm{X}}+\mathrm{g}_{\mathrm{Y}}\right) / 2$ is not yet observed at $250 \mathrm{~K}$. In systems with a static JTE, $\mathrm{T}_{\mathrm{t}}$ has been shown to reflect the barrier among equivalent distortions and so $T_{t}=160 \mathrm{~K}$ for KCl: $\mathrm{Ag}^{2+}$ is related to a calculated barrier $B=0.12 \mathrm{eV}{ }^{27}$. The present calculations on $\left(\mathrm{CH}_{3} \mathrm{NH}_{3}\right)_{2} \mathrm{CdCl}_{4}: \mathrm{Cu}^{2+}$ giving $B=0.40 \mathrm{eV}$ are thus qualitatively consistent with the lack of an average signal at $\mathrm{T}=250 \mathrm{~K}$.

As a salient feature, the small experimental $g_{z}-g_{0}=0.05$ shift suggests that, despite the orthorhombic distortion in $\left(\mathrm{CH}_{3} \mathrm{NH}_{3}\right)_{2} \mathrm{CdCl}_{4}: \mathrm{Cu}^{2+}$, the wavefunction of the unpaired electron keeps a dominant $\sim 3 z^{2}-r^{2}$ character ${ }^{68}$. The $D_{4 h} \rightarrow D_{2 h}$ symmetry lowering makes that the orbital $\sim 3 z^{2}-r^{2}$ can be hybridized with the $\sim x^{2}-y^{2}$ one and thus the wavefunction, $|\varphi\rangle$, of the unpaired electron can shortly be written as

$$
|\varphi\rangle=\lambda\left|\sim 3 z^{2}-r^{2}\right\rangle+\mu\left|\sim x^{2}-y^{2}\right\rangle
$$

where $\lambda^{2}+\mu^{2}=1$. As an electron in a pure $3 z^{2}-r^{2}$ orbital and $D_{4 h}$ symmetry gives no contribution to $g_{z}-g_{0}$ in second-order perturbations ${ }^{69}$ the positive experimental $g_{z}-g_{0}=$ 0.05 value found in $\left(\mathrm{CH}_{3} \mathrm{NH}_{3}\right)_{2} \mathrm{CdCl}_{4}: \mathrm{Cu}^{2+}$ can mainly be ascribed to the admixture embodied in Eq. (1) induced by the $D_{4 h} \rightarrow D_{2 h}$ symmetry reduction. In systems like $\mathrm{NaCl}: \mathrm{Cu}^{2+}$ the unpaired electron of the $\mathrm{CuCl}_{6}{ }^{4-}$ unit resides in a pure $\sim \mathrm{x}^{2}-\mathrm{y}^{2}$ orbital as a result of an elongated tetragonal symmetry induced by a static $\mathrm{JTE}^{24,28}$. As in that case it 
has been measured $g_{z}\left(x^{2}-y^{2}\right)=2.37$ then we can estimate $\mu^{2} \cong 13 \%$ for $\left(\mathrm{CH}_{3} \mathrm{NH}_{3}\right)_{2} \mathrm{CdCl}_{4}: \mathrm{Cu}^{2+}$. Moreover, it has been pointed out ${ }^{69}$ that $\mu$ can also be estimated from experimental $g_{Y}-g_{x}$ and $<g>$ values through the relation

$$
g_{Y}-g_{X} \cong(4 \mu / \sqrt{3})\left(<g>-g_{0}\right)
$$

If we use the experimental values $g_{Y}-g_{X}=0.21$ and $\langle g\rangle-g_{0}=0.24{ }^{40}$ we estimate $\mu^{2} \cong$ $14 \%$. These facts thus prove that the wavefunction of the unpaired electron actually has a dominant $\sim 3 z^{2}-r^{2}$ character thus implying that the density along the $Z$ axis is different from that along $\mathrm{Y}$ or $\mathrm{X}$ axes. This conclusion is thus in agreement with the axial character displayed by layered lattices like $\left(\mathrm{CH}_{3} \mathrm{NH}_{3}\right)_{2} \mathrm{CdCl}_{4}$.

It is worth noting that an orthorhombic instability similar to that found for $\left(\mathrm{CH}_{3} \mathrm{NH}_{3}\right)_{2} \mathrm{CdCl}_{4}: \mathrm{Cu}^{2+}$ has also been observed in another insulating compound doped with $\mathrm{Cu}^{2+}$. Indeed in $\mathrm{NH}_{4} \mathrm{Cl}$ crystals grown in acidic solutions the $\mathrm{CuCl}_{4}\left(\mathrm{H}_{2} \mathrm{O}\right)_{2}{ }^{2-}$ complex is formed whose local symmetry below $T=20 \mathrm{~K}$ is not tetragonal but orthorhombic ${ }^{69-72}$. Again, if $\mathrm{Z}$ corresponds to the $\mathrm{Cu}^{2+}-\mathrm{O}^{2-}$ direction the wavefunction of the unpaired electron has been proved to display a strong $\sim 3 z^{2}-r^{2}$ character ${ }^{69,71}$. Indeed, it has been derived $\mu^{2} \cong 10 \%$ although the estimated orthorhombic distortion $R_{L}-R_{S} \cong 0.50 \AA$ is a bit higher than that calculated for $\left(\mathrm{CH}_{3} \mathrm{NH}_{3}\right)_{2} \mathrm{CdCl}_{4}: \mathrm{Cu}^{2+69}$.

The instability in the equatorial plane of $\left(\mathrm{CH}_{3} \mathrm{NH}_{3}\right)_{2} \mathrm{CdCl}_{4}: \mathrm{Cu}^{2+}$ under a local tetragonal symmetry is helped by an equatorial $\mathrm{Cu}^{2+}-\mathrm{Cl}^{-}$distance, $\mathrm{R}_{S}=\mathrm{R}_{\mathrm{L}}=2.56 \AA$ (Table 4), which is $\sim 0.20 \AA$ higher than that for an elongated $\mathrm{CuCl}_{6}{ }^{4-}$ unit ${ }^{65}$. This fact tends to reduce the force constant of the $B_{1 \mathrm{~g}}$ local mode. Moreover, there is a negative contribution to the ground state force constant ${ }^{66}$ that plays a key role for reaching an unstable situation, a matter commented on in section 3.5. The microscopic origin of the orthorhombic instability of $\mathrm{CuCl}_{4}\left(\mathrm{H}_{2} \mathrm{O}\right)^{2-}$ complex in $\mathrm{NH}_{4} \mathrm{Cl}$ has previously been discussed in some detail $^{69}$.

\subsection{Origin of the ground state and equilibrium geometry in pure layered compounds containing $\mathrm{Cu}^{2+}$}

We have seen in the preceding section that the local geometry and ground state of $\left(\mathrm{CH}_{3} \mathrm{NH}_{3}\right)_{2} \mathrm{CdCl}_{4}: \mathrm{Cu}^{2+}$ are governed by two main factors: (1) An internal electric field that under an imposed $D_{4 h}$ symmetry $\left(R_{L}=R_{S}\right)$ places the hole in the $\sim 3 z^{2}-r^{2}$ orbital thus favoring a compressed geometry. (2) An additional orthorhombic instability, induced by a negative force constant of the local $B_{1 g}$ mode, making $R_{L} \neq R_{s}$ but keeping the hole in an orbital with a dominant $\sim 3 z^{2}-r^{2}$ character. We are going to see that these ideas also explain the local geometry observed for pure copper layered compounds and the associated electronic ground state.

Indeed, in inorganic layered compounds like $\mathrm{K}_{2} \mathrm{CuF}_{4}$ or $\mathrm{Rb}_{2} \mathrm{CuCl}_{4}$ the shape of $\mathrm{V}_{\mathrm{R}}(\mathbf{r}$ ) (Figs. 2 and 3 ) is similar to that found for a hybrid layered compound (Fig. 6). The axial form of this potential would place the hole in a $\sim 3 z^{2}-r^{2}$ orbital thus favoring a local compressed tetragonal geometry ${ }^{56}$. For this reason, we have calculated the $\mathrm{Cu}^{2+} \mathrm{X}^{-}$ distances in $\mathrm{K}_{2} \mathrm{CuF}_{4}$ and $\mathrm{Rb}_{2} \mathrm{CuCl}_{4}$ assuming the higher symmetry $14 / \mathrm{mmm}$ of the parent 
structure $\mathrm{K}_{2} \mathrm{NiF}_{4}$, and thus the local geometry around $\mathrm{Cu}^{2+}$ is tetragonal. As shown in Table 1 , in such a case we obtain a compressed tetragonal geometry around $\mathrm{Cu}^{2+}$. However, the calculations also prove that the tetragonal $14 / \mathrm{mmm}$ is not stable. In the case of $\mathrm{K}_{2} \mathrm{CuF}_{4}$ we have found a local $\mathrm{B}_{1 \mathrm{~g}}$ mode with imaginary frequency $\hbar \omega\left(\mathrm{B}_{1 \mathrm{~g}}\right)=303 i$ $\mathrm{cm}^{-1}$. Therefore, the associated force constant is negative and thus the lattice is not stable with respect to a local orthorhombic distortion. By contrast, when calculations on $\mathrm{K}_{2} \mathrm{CuF}_{4}$ and $\mathrm{Rb}_{2} \mathrm{CuCl}_{4}$ are carried out without any restriction we obtain a stable situation for the Cmca structure (Table 1).

It is worth noting now that the orthorhombic distortion derived for $\left(\mathrm{CH}_{3} \mathrm{NH}_{3}\right)_{2} \mathrm{CdCl}_{4}: \mathrm{Cu}^{2+}$ (Table 4) is clearly smaller than that measured for $\mathrm{RCuCl}_{4}$ pure compounds (Table 3). Indeed, the calculated $\mathrm{R}_{\mathrm{L}}-\mathrm{RS}_{\mathrm{S}}=0.25 \AA$ value for $\left(\mathrm{CH}_{3} \mathrm{NH}_{3}\right)_{2} \mathrm{CdCl}_{4}: \mathrm{Cu}^{2+}$ is $\sim 2.5$ times smaller than the figure reported for pure $\mathrm{RCuCl}_{4}$ compounds (Table 3). Similarly, there is an orthorhombic instability in the pure compound $\mathrm{K}_{2} \mathrm{CuF}_{4}$ while it is absent in $\mathrm{K}_{2} \mathrm{ZnF}_{4}: \mathrm{Cu}^{2+}$ where the local structure corresponds to a compressed octahedron ${ }^{54}$.

Seeking to shed light on this issue, we have calculated the $\mathrm{B}_{1 \mathrm{~g}}$ frequency on $\mathrm{K}_{2} \mathrm{Cu}_{\mathrm{x}} \mathrm{Zn}_{1-\mathrm{x}} \mathrm{F}_{4}$ mixed crystals. For $x \approx 0\left(\mathrm{~K}_{2} \mathrm{ZnF}_{4}\right) \hbar \omega\left(\mathrm{B}_{1 \mathrm{~g}}\right)=317 \mathrm{~cm}^{-1}$ and for $\mathrm{x}=0.25 \hbar \omega\left(\mathrm{B}_{1 \mathrm{~g}}\right)=84 \mathrm{~cm}^{-1}$ but when $x=0.75 \hbar \omega\left(B_{1 g}\right)=416 i \mathrm{~cm}^{-1}$, that is, the orthorhombic instability comes out. These results thus suggest that the orthorhombic distortion can appear more easily in layered $\mathrm{Cu}^{2+}$ compounds which share ligands than in the case of isolated $\mathrm{CuX}_{6}{ }^{4-}$ complexes $(\mathrm{X}=\mathrm{F}, \mathrm{Cl})$ embedded in host lattices with closed shell cations like $\mathrm{Zn}^{2+}$ or $\mathrm{Cd}^{2+}$. This relevant issue is discussed in the next section.

As regards the nature of the ground state, the available experimental gz values ${ }^{41,73-75}$ for the $\mathrm{RCuCl}_{4}$ compounds (Table 3) essentially coincide with the experimental figure $\mathrm{g}_{z}=$ 2.05 for $\left(\mathrm{CH}_{3} \mathrm{NH}_{3}\right)_{2} \mathrm{CdCl}_{4}: \mathrm{Cu}^{2+}$, a fact that suggests an unpaired electron in a mainly $\sim 3 z^{2}-$ $\mathrm{r}^{2}$ orbital. In other words, although the orthorhombic distortion in $\mathrm{RCuCl}_{4}$ compounds, $\mathrm{R}_{\mathrm{L}}-\mathrm{R}_{\mathrm{S}} \sim 0.65 \AA$, is clearly higher than that for $\left(\mathrm{CH}_{3} \mathrm{NH}_{3}\right)_{2} \mathrm{CdCl}_{4}: \mathrm{Cu}^{2+}$, where $\mathrm{Cu}^{2+}$ enters as impurity, in both cases the wavefunction of the unpaired electron keeps a dominant $3 z^{2}$ $r^{2}$ character. This standpoint is confirmed by the present calculations on $\left(\mathrm{CH}_{3} \mathrm{NH}_{3}\right)_{2} \mathrm{CuCl}_{4}$ leading to a wavefunction of the unpaired electron with $\sim 80 \%$ of $3 z^{2}-r^{2}$ character, a fact that can partially be connected with an out-of-plane distance, $R_{z}$, which is nearly unmodified on passing from the doped to the pure $\mathrm{RCuCl}_{4}$ compounds (Table 3). A support to this idea also comes from previous calculations on $\mathrm{CuCl}_{4}\left(\mathrm{H}_{2} \mathrm{O}\right)_{2}{ }^{2-}$ units in $\mathrm{NH}_{4} \mathrm{Cl}$ yielding $\mu^{2} \cong 15 \%$ even if $\mathrm{R}_{\mathrm{L}}-\mathrm{RS}_{\mathrm{S}}=0.65 \AA^{69}$.

The situation found for $\mathrm{K}_{2} \mathrm{CuF}_{4}$ is rather similar to that for $\mathrm{RCuCl}_{4}$ compounds. Indeed, the wavefunction of the unpaired electron at the equilibrium geometry has been shown ${ }^{42}$ to exhibit a dominant $\sim 3 z^{2}-r^{2}$ character $\left(\mu^{2} \cong 17 \%\right)$ in spite of the orthorhombic distortion described by $R_{L}-R_{S}=0.29 \AA$ (Table 1 ). This value of the hybridization coefficient, $\mu$, is consistent with the experimental value $g_{z}=2.08$ for $\mathrm{K}_{2} \mathrm{CuF}_{4}{ }^{32}$ and the value $g_{z}=2.65$ measured for $\mathrm{CsCdF}_{3}: \mathrm{Cu}^{2+20,76}$ where the unpaired electron of the $\mathrm{CuF}_{6}{ }^{4-}$ unit lies in a pure $\sim x^{2}-y^{2}$ orbital. 
Bearing in mind the present reasoning and previous results on copper layered materials, we see that an applied pressure tends to suppress the orthorhombic distortion and not the JTE such as it is widely said in the scientific literature ${ }^{14,15,30,31,33,35}$. It should be noted that in a genuine JTE system pressure can promote the transition from a static to a dynamic regime with coherent tunneling among the equivalent distortions ${ }^{28,77}$. Even in that regime, pressure can increase the value of the tunneling splitting but it will never destroy the JTE ${ }^{29,77}$.

\subsection{Origin of the the orthorhombic instability in pure and doped compounds}

As discussed in the previous section, the orthorhombic instability displayed by pure compounds like $\left(\mathrm{CH}_{3} \mathrm{NH}_{3}\right)_{2} \mathrm{CuCl}_{4}$ or $\mathrm{K}_{2} \mathrm{CuF}_{4}$ is either smaller or not observed in doped systems like $\left(\mathrm{CH}_{3} \mathrm{NH}_{3}\right)_{2} \mathrm{CdCl}_{4}: \mathrm{Cu}^{2+}$ or $\mathrm{K}_{2} \mathrm{ZnF}_{4}: \mathrm{Cu}^{2+}$. It is thus relevant to clear up the kind of cooperative effect favoring the instability of pure layered compounds with respect to systems where $\mathrm{Cu}^{2+}$ enters as impurity.

A non-symmetric distortion mode of a molecule is unstable if the associated force constant, $\mathrm{K}$, of the ground state is negative. In general, there are two contributions to $\mathrm{K}$ 66. One, termed $K_{0}$, is only related to the wavefunction, $\Psi_{0}$, corresponding to the undistorted situation. By contrast, the other one reflects the changes of the wavefunction driven by the distortion and the electron-vibration coupling ${ }^{66}$. That contribution is negative for the ground state and is termed $-\mathrm{K}_{\mathrm{v}}$, so $\mathrm{K}=\mathrm{K}_{0}-\mathrm{K}_{\mathrm{v}}$. Accordingly, the condition for instability is simply $K_{v}>K_{0}$. Now, as $K_{v}$ reflects the admixture of excited states with $\Psi_{0}$ through the electron-vibration coupling, this quantity is more important for $\mathrm{Cu}^{2+}$ complexes than for those cations with closed shell configuration, like $\mathrm{Zn}^{2+}$ or $\mathrm{Cd}^{2+}$, where first excitations appear, in general, at higher energies. Thus, if we designate by $\mathrm{K}_{\mathrm{v}}$ (open) and $\mathrm{K}_{\mathrm{v}}$ (close) the contribution for complexes with open or closed shell cations we expect $\mathrm{K}_{v}$ (open) $>$ $\mathrm{K}_{\mathrm{v}}$ (close).

When $\mathrm{Cu}^{2+}$ enters as impurity in a lattice like $\mathrm{K}_{2} \mathrm{ZnF}_{4}$ the electronic density is localized in the complex formed with nearest anions. If we now consider the $\mathrm{B}_{1 \mathrm{~g}}$ mode (Fig. 8) described by the $Q$ coordinate

$$
\mathrm{Q}=(1 / 2)\left(\mathrm{u}_{1}-\mathrm{u}_{2}+\mathrm{u}_{3}-\mathrm{u}_{4}\right) \quad \mathrm{u}_{1}=-\mathrm{u}_{2}=\mathrm{u}_{3}=-\mathrm{u}_{4}=\mathrm{u}
$$

the variation of elastic energy associated with the complex is just given by $2\left[K_{0}\right.$ $\mathrm{K}_{\mathrm{v}}$ (open)] $\mathrm{u}^{2}$. It should be remarked now that as the complex is embedded in a lattice (Fig. 8) the motion of ligands also imply the activation of springs associated with $\mathrm{M}^{2+}-\mathrm{X}^{-}$ bonds $(M=Z n)$ giving rise to an additional contribution to the elastic energy. If, for simplicity, we assume the same value of $\mathrm{K}_{0}$ for $\mathrm{Cu}^{2+}$ and $\mathrm{M}^{2+}$ complexes this contribution is just given by $2\left[\mathrm{~K}_{0}-\mathrm{K}_{\mathrm{v}}(\right.$ close $\left.)\right] \mathrm{u}^{2}$. Accordingly, the requirement for a negative value for the total elastic energy is

$$
\left.\mathrm{Kv}_{\mathrm{v}} \text { (open }\right)+\mathrm{Kv}_{\mathrm{v}} \text { (close) }>2 \mathrm{~K}_{0}
$$

Nevertheless, if we consider a pure compound of $\mathrm{Cu}^{2+}$ (Fig. 8) and activate the $\mathrm{B}_{1 \mathrm{~g}}$ mode for every complex the elastic energy per complex is $2\left[\mathrm{~K}_{0}-\mathrm{Kv}_{\mathrm{v}}\right.$ (open) $] \mathrm{u}^{2}$ and the instability condition is 


$$
K_{v}(\text { open })>K_{0}
$$

Thus, if $\mathrm{K}_{\mathrm{V}}$ (open) $\gg>\mathrm{K}_{\mathrm{v}}$ (close) the instability can appear more easily in a pure compound than for an isolated impurity.

As we have seen, in the present layered $\mathrm{Cu}^{2+}$ compounds the internal electric field favors, in principle a compressed conformation where the equatorial metal-ligand distance, $R_{S}$ $=\mathrm{R}_{\mathrm{L}}$, is higher than the axial distance, $\mathrm{R}_{\mathrm{z}}$. This fact alone helps to decrease the value of $K_{0}$ corresponding to the $B_{1 g}$ mode that involves only equatorial ligands thus favoring the appearance of the instability ${ }^{69,42}$.

The origin of $\mathrm{KV}$ (open) in the case of $\mathrm{CuCl}_{4}\left(\mathrm{H}_{2} \mathrm{O}\right)_{2}{ }^{2-}$ complexes in $\mathrm{NH}_{4} \mathrm{Cl}$ has previously been explored showing that $\mathrm{Cl}^{-} \rightarrow \mathrm{Cu}^{2+}$ charge transfer excitations are responsible for the observed orthorhombic distortion ${ }^{69}$. A general view on the origin of $\mathrm{K}_{0}$ and $\mathrm{K}_{\mathrm{v}}$ contributions is provided in Ref. ${ }^{78}$.

\section{FINAL REMARKS}

In this work we have derived from first-principles calculations the pressure dependence of $\mathrm{Cu}^{2+}-\mathrm{X}^{-}(\mathrm{X}=\mathrm{Cl}, \mathrm{F})$ distances in copper layered compounds. As up to now there are not reliable experimental data on the sensitivity to pressure of $R_{Z}, R_{S}$ and $R_{L}$ distances the information provided in this work can be valuable for a further insight into properties displayed by these layered systems and in particular the large piezochromic effect observed in $\mathrm{RCuCl}_{4}$ compounds ${ }^{14-16}$.

As a main result, we have shown in this work that neither the local structure nor the ground state of copper layered compounds can properly be understood under the widely followed assumption of a JTE. Indeed, we have proved that they are strongly influenced by the anisotropic internal field and an additional orthorhombic instability in the layer plane.

The results of this work stress the importance played by the internal electric field, $E_{R}(r)$, for a proper understanding of materials containing transition metal complexes. Indeed, that field is greatly responsible for the different ground state of $\mathrm{K}_{2} \mathrm{CuF}_{4}$ and $\mathrm{La}_{2} \mathrm{CuO}_{4} 42$ as well as for the color of $\mathrm{Cr}^{3+}$-based gemstones ${ }^{57}$ and the Egyptian Blue pigment ${ }^{79}$. As $\mathbf{E}_{\mathrm{R}}(\mathbf{r})$ induces shifts up to $\sim 1 \mathrm{eV}$ on optical transitions ${ }^{67}$ the properties of transition metal systems cannot, in general, be understood considering only the isolated complex. Despite these facts, the influence of this internal field in the interpretation of data from transition metal compounds is still often ignored ${ }^{80}$.

The existence of $d^{9}$ systems with a hole in a $\sim 3 z^{2}-r^{2}$ orbital in the ground state has been questioned ${ }^{36}$. The examples given in this work show that such a situation can actually happen. Moreover, even in cases where a genuine JTE takes place one cannot discard a compressed octahedron as equilibrium geometry with a hole in the $\sim 3 z^{2}-r^{2}$ level. This situation has been found for $\mathrm{CaO}: \mathrm{Ni}^{+81}$, as recently proved ${ }^{82}$.

The present ideas can also be of interest to explain the properties of $\mathrm{Ag}^{2+}$ layered compounds, like $\mathrm{Cs}_{2} \mathrm{AgF}_{4}$, deeply investigated in the last years ${ }^{36,83-85}$. Calculations carried 
out on $\mathrm{Cs}_{2} \mathrm{AgF}_{4}$ support that the local structure and ground state of the $\mathrm{AgF}_{6}{ }^{4-}$ complex arise from the same causes discussed in this work for $\mathrm{K}_{2} \mathrm{CuF}_{4}$ involving an axial internal electric field and a subsequent orthorhombic distortion in the layer plane. In accord with this view a value $g_{z}=2.07$ has recently been measured by EPR for $\mathrm{Cs}_{2} \mathrm{AgF}_{4}{ }^{85}$, again compatible with a hole with a dominant $3 z^{2}-r^{2}$ character.

The local structure in the present layered compounds is found to be independent on the magnetic order. Supporting this view, the calculated $\mathrm{Cu}^{2+}-\mathrm{F}^{-}$distances in $\mathrm{K}_{2} \mathrm{CuF}_{4}$ vary relatively by less than $5 \cdot 10^{-4}$ on passing from a ferromagnetic to an antiferromagnetic order while the energy difference between these two configurations is equal only to 5 meV. This figure is thus much smaller than the energy gain due to the internal electric field or the orthorhombic instability, which are both in the range 0.1-1 eV. According to this argument, it can hardly be accepted that the orbital ordering and local structure in a layered compound like $\mathrm{K}_{2} \mathrm{CuF}_{4}$ are not determined ${ }^{42}$ by the weak exchange interactions, which is the foundation of the Kugel-Khomskii model ${ }^{86}$. This conclusion is reinforced by performing an analysis of the atomic orbital contributions for the various magnetic states that yield very similar results. In this way we can resolve that our initial conclusions are independent of the spin state of the lattice as a whole.

As a final comment, the results reached in this work open a window for a proper understanding of the unusual ferromagnetism of the copper layered compounds and the surprising piezochromism displayed by these materials. Indeed, experimental results prove that charge transfer transitions are red-shifted by an applied pressure ${ }^{14,15}$. This fact is in principle puzzling as experimental $\left.\right|^{87}$ and theoretical data ${ }^{88}$ on charge transfer transitions of square-planar $\mathrm{CuCl}_{4}{ }^{2-}$ complexes show that they move to the blue when the $\mathrm{Cu}^{2+}-\mathrm{Cl}^{-}$distance is contracted. A similar blue shift is found for charge transfer transitions of octahedral or tetrahedral complexes ${ }^{89}$.

Further work searching to explain the puzzling red shift found in copper layered compounds is now under way.

\section{AUTHOR INFORMATION}

\section{Corresponding author}

*E-mail: aramburj@unican.es

\section{Notes}

The authors declare no competing financial interest.

\section{ACKNOWLEDGEMENTS}

The support by the Spanish Ministerio de Ciencia y Tecnología under Projects FIS201230996 and FIS2015-64886-C5-2-P is acknowledged.

\section{REFERENCES}


1. Berry, J.; Buonassisi, T.; Egger, D. A.; Hodes, G.; Kronik, L.; Loo, Y.-L.; Lubomirsky, I.; Marder, S. R.; Mastai, Y.; Miller, J. S.; et al., Hybrid Organic-Inorganic Perovskites (HOIPs): Opportunities and Challenges, Adv. Mater. 2015, 27, 5102-5112.

2. Park, N.-G.; Grätzel, M.; Miyasaka, T., Eds. Organic-Inorganic Halide Perovskite Photovoltaics. From Fundamentals to Device Architectures; Springer: 2016.

3. Li, W.; Wang, Z.; Deschler, F.; Gao, S.; Friend, R. H.; Cheetham, A. K., Chemically Diverse and Multifunctional Hybrid Organic-Inorganic Perovskites, Nature Rev. Mat. 2017, 2, 16099.

4. A. K. Cheetham, A. K.; Rao, C. N. R., There's Room in the Middle, Science 2007, 318, 58-59.

5. Stroppa, A.; Barone, P.; Jain, P.; Perez-Mato, J. M.; Picozzi, S., Hybrid Improper Ferroelectricity in a Multiferroic and Magnetoelectric Metal-Organic Framework, Adv. Mat. 2013, 25, 2284-2290.

6. Kim, H.-S.; Im, S. H.; Park, N.-G., Organolead Halide Perovskite: New Horizons in Solar Cell Research. J. Phys. Chem. C 2014, 118, 5615-5625.

7. Stoddard, R. J.; Eickemeyer, F. T.; Katahara, J. K.; Hillhouse, H. W., Correlation between Photoluminescence and Carrier Transport and a Simple In Situ Passivation Method for High-Bandgap Hybrid Perovskites. J. Phys. Chem. Lett. 2017, 8, 3289-3298.

8. Li, X.; Zhong, X.; Hu, Y.; Li, B.; Sheng, Y.; Zhang, Y.; Weng, C.; Feng, M.; Han, H.; Wang, J., Organic-Inorganic Copper(II)-Based Material: A Low-Toxic, Highly Stable Light Absorber for Photovoltaic Application, J. Phys. Chem. Lett. 2017, 8, 1804-1809.

9. Cortecchia, D.; Dewi, H. A.; Yin, J.; Bruno, A.; Chen, S.; Baikie, T.; Boix, P. P.; Grätzel, M.; Mhaisalkar, S.; Soci, C.; Mathews, N., Lead-Free $\mathrm{MA}_{2} \mathrm{CuCl}_{x} \mathrm{Br}_{4-x}$ Hybrid Perovskites, Inorg. Chem. 2016, 55, 1044-1052.

10. Polyakov, A. O.; Arkenbout, A. H.; Baas, J.; Blake, G. R.; Meetsma, A.; Caretta, A.; van Loosdrecht, P. W. H.; Palstra, T. T. M., Coexisting Ferromagnetic and Ferroelectric Order in a $\mathrm{CuCl}_{4}$-based Organic-Inorganic Hybrid. Chem. Mater. 2012, 24, 133-139.

11. Huang, B.; Wang, B.-Y.; Du, Z.-Y.; Xue, W.; Xu, W.-J.; Su, Y.-J.; Zhang, W.-X.; Zeng, M.H.; Chen, X.-M., Importing Spontaneous Polarization into a Heisenberg Ferromagnet for a Potential Single-Phase Multiferroic. J. Mat. Chem. C. 2016, 4, 8704-8710.

12. Kundys, B.; Lappas, A.; Viret, M.; Kapustianyk, V.; Rudyk, V.; Semak, S.; Simon, Ch.; Bakaimi, I., Multiferroicity and Hydrogen-Bond Ordering in $\left(\mathrm{C}_{2} \mathrm{H}_{5} \mathrm{NH}_{3}\right)_{2} \mathrm{CuCl}_{4}$ Featuring Dominant Ferromagnetic Interactions. Phys. Rev. B 2010, 81, 224434.

13. Jaffe, A.; Karunadasa, H. I., Lithium Cycling in a Self-Assembled Copper Chloride-Polyether Hybrid Electrode. Inorg. Chem. 2014, 53, 6494-6496.

14. Jaffe, A.; Lin, Y.; Mao, W. L.; Karunadasa, H. I., Pressure-Induced Conductivity and Yellow-to-Black Piezochromism in a Layered $\mathrm{Cu}-\mathrm{Cl}$ Hybrid Perovskite. J. Am. Chem. Soc. 2015, 137, 1673-1678.

15. Gupta, S.; Pandey, T.; Singh, A. K., Suppression of Jahn-Teller Distortions and Origin of Piezochromism and Thermochromism in $\mathrm{Cu}-\mathrm{Cl}$ Hybrid Perovskite. Inorg. Chem. 2016, 55, 6817-6824.

16. Caretta, A.; Miranti, R.; Arkenbout, A. H.; Polyakov, A. O.; Meetsma, A.; Hidayat, R.; Tjia, M. O.; Palstra, T. T. M.; van Loosdrecht, P. H. M., Thermochromic Effects in a 
Jahn-Teller Active $\mathrm{CuCl}_{6}{ }^{4-}$ Layered Hybrid System. J. Phys.: Condens. Matter 2013, 25 505901-505906.

17. Pabst, I.; Fuess, H.; Bats, J. W., Structure of Monomethylammonium Tetrachlorocuprate at 297 and 100 K. Acta Cryst. C 1987, 43, 413-416.

18. Steadman, J. P.; Willett, R. D., The Crystal Structure of $\left(\left(\mathrm{C}_{2} \mathrm{H}_{5} \mathrm{NH}_{3}\right)_{2} \mathrm{CuCl}\right.$. Inorganica Chimica Acta 1970, 4, 367-371.

19. Barendregt, F.; Schenk, H., The Crystal Structure of $\left(\mathrm{C}_{3} \mathrm{H}_{7} \mathrm{NH}_{3}\right)_{2} \mathrm{CuCl}_{4}$. Physica 1970, 49, 465-468.

20. Minner, E. M. C., Etude Spectroscopique des Ions Jahn-Teller Cuivre et Argent Bivalents dans des Monocristaux de Fluoroperovskites de Composition Chimique $\mathrm{AMF}_{3}$. Ph.D. Thesis, 1993, University of Geneva.

21. Dubicki, L.; Riley, M. J.; Krausz, E. R. Electronic-Structure of the Copper(II) Ion Doped in Cubic KZnF3. J. Chem. Phys. 1994, 101, 1930-1938.

22. Garcia-Fernandez, P.; Barriuso, M. T.; Garcia-Lastra, J. M.; Moreno, M.; Aramburu, J. A. Compounds Containing Tetragonal $\mathrm{Cu}^{2+}$ Complexes: Is the $d x^{2}-y^{2}-d 3 z^{2}-r^{2}$ Gap a Direct Reflection of the Distortion? J. Phys. Chem. Lett. 2013, 4, 2385-2390.

23. Aramburu, J. A.; García-Fernández, P.; García-Lastra, J. M.; Moreno, M. Jahn-Teller and Non-Jahn-Teller Systems Involving $\mathrm{CuF}_{6}{ }^{4-}$ Units: Role of the Internal Electric Field in $\mathrm{Ba}_{2} \mathrm{ZnF}_{6}: \mathrm{Cu}^{2+}$ and Other Insulating Systems. J. Phys. Chem. C 2017, 121, 5215-5224.

24. Borcherts, R. H.; Kanzaki, H.; Abe, H. EPR Spectrum of a Jahn-Teller System, NaCl$\mathrm{Cu}^{2+}$. Phys. Rev. B 1970, 2, 23-27.

25. Bill, H., Observation of the Jahn-Teller Effect with Electron Paramagnetic Resonance. In The Dynamical Jahn-Teller Effect in Localized Systems, Perlin, Y. E., Wagner, M., Eds., Elsevier: Amsterdam, 1984.

26. Sierro, J. Paramagnetic Resonance of the $\mathrm{Ag}^{2+}$ Ion in Irradiated Alkali Chlorides. J. Phys. Chem. Solids 1967, 28, 417-422.

27. Trueba, A.; Garcia-Lastra, J. M.; de Graaf, C.; Garcia-Fernandez,P.; Barriuso, M. T.; Aramburu, J. A.; Moreno, M. Jahn-Teller Effect in $\mathrm{Ag}^{2+}$ Doped $\mathrm{KCl}$ and $\mathrm{NaCl}$ : Is There any Influence of the Host Lattice? Chem. Phys. Lett. 2006, 430, 51-55.

28. Ham, F. S. Jahn-Teller Effects in EPR spectra. In Electron Paramagnetic Resonance, Geschwind, S., Ed.; Plenum: New York, 1972.

29. Garcia-Fernandez, P.; Trueba, A.; Barriuso, M. T.; Aramburu, J.A.; Moreno, M. Dynamic and Static Jahn-Teller Effect in Impurities: Determination of the Tunneling Splitting. Prog. Theor. Chem. Phys. 2011, 23, 105-142.

30. Moritomo, Y.; Tokura, Y., Pressure-Induced Disappearance of the In-Plane Lattice Distortion in Layered Cupric Chloride $\left(\mathrm{C}_{2} \mathrm{H}_{5} \mathrm{NH}_{3}\right)_{2} \mathrm{CuCl}_{4}$. J. Chem. Phys. 1994, 101, 1763-1766.

31. Ohwada, K.; Ishii, K.; Inami, T.; Murakami, Y.; Shobu, T.; Ohsumi, H.; Ikeda, N.; Yasuo Ohishi, Y., Structural Properties and Phase Transition of Hole-Orbital-Ordered $\left(\mathrm{C}_{2} \mathrm{H}_{5} \mathrm{NH}_{3}\right)_{2} \mathrm{CuCl}_{4}$ Studied by Resonant and Non-Resonant X-Ray Scatterings under High Pressure. Phys. Rev. B 2005, 72, 014123.

32. Yamada, I., Magnetic Properties of $\mathrm{K}_{2} \mathrm{CuF}_{4}$ : A Transparent Two-Dimensional Ferromagnet. J. Phys. Soc. Jpn. 1972, 33, 979-988. 
33. Kleemann, W.; Farge I., Optical Properties and Ferromagnetic order in $\mathrm{K}_{2} \mathrm{CuF}_{4}$. Journal de Physique 1975, 36, 1293-1304.

34. Hidaka, M.; Inoue, K.; Yamada, I.; Walker, P. J., X-ray Diffraction Study of the Crystal Structures of $\mathrm{K}_{2} \mathrm{CuF}_{4}$ and $\mathrm{K}_{2} \mathrm{Cu}_{x} \mathrm{Zn}_{1-\mathrm{x}} \mathrm{F}_{4}$. Physica $B$ 1983, 121, 343-350.

35. Aguado, F.; Rodrıguez, F.; Valiente, R.; Hanfland, M.; Itie, J. P., Variation of the JahnTeller Distortion with Pressure in the Layered Perovskite $\mathrm{Rb}_{2} \mathrm{CuCl}_{4}$ : Local and Crystal Compressibilities. J. Phys.: Condens. Matter 2007, 19, 346229-346238.

36. McLain, S. E.; Dolgos, M. R.; Tennant, D. A.; Turner, J. F. C.; Barnes, T.; Proffen, T.; Sales, B. C.; Bewley, R. I., Magnetic Behaviour of Layered Ag(II) Fluorides. Nature Mater. 2006, 5, 561-566.

37. Carlson, S.; Xu, Y.; Hålenius, U.; Norrestam, R., A Reversible, Isosymmetric, HighPressure Phase Transition in $\mathrm{Na}_{3} \mathrm{MnF}_{6}$. Inorg. Chem. 1998, 37, 1486-1492.

38. Charles, N.; Rondinelli, J. M., Microscopic Origin of Pressure-Induced Isosymmetric Transitions in Fluoromanganate Cryolites. Phys. Rev. B 2014, 90, 094114.

39. Ishizuka, M.; Terai, M.; Hidaka, M.; Endo, S.; Yamada, I.; Shimomura, O., PressureInduced Structural Phase Transition in the Two-Dimensional Heisenberg Ferromagnet $\mathrm{K}_{2} \mathrm{CuF}_{4}$. Phys. Rev. B 1998, 57, 64-67.

40. Valiente, R.; Lezama, L. M.; Rodriguez, F.; Moreno, M., Study of Bidimensional $\left(\mathrm{CH}_{3} \mathrm{NH}_{3}\right)_{2} \mathrm{CdCl}_{4}: \mathrm{Cu}^{2+}$ and $\left(\mathrm{CH}_{3} \mathrm{NH}_{3}\right)_{2} \mathrm{CuCl}_{4}$. Materials Science Forum 1997, 239-241, 729-732.

41. Valiente, R.; Rodriguez, F.; Moreno, M.; R. Lezama, L. M., EPR study of $\mathrm{Cu}^{2+}$ doped $\left(\mathrm{C}_{n} \mathrm{H}_{2 n+1} \mathrm{NH}_{3}\right)_{2} \mathrm{CdCl}_{4}(\mathrm{~N}=1,3)$ with layer structure. In Vibronic Interactions: Jahn-Teller Effect in Crystals and Molecules, Ed. Kaplan, M. D.; Zimmerman, G. O., Kluwer Academic Publishers 2001, 221-228.

42. Garcia-Fernandez, P.; Moreno, M.; Aramburu, J. A. Electrostatic Control of Orbital Ordering in Noncubic Crystals. J. Phys. Chem. C 2014, 118, 7554-7561.

43. CRYSTAL basis sets http://www.crystal.unito.it/Basis Sets/Ptable.html access 6 February 2018.

44. Peintinger, M. F.; Oliveira, D. V.; Bredow, T. J. Consistent Gaussian Basis Sets of Triple-Zeta Valence with Polarization Quality for Solid-State Calculations. Comput. Chem. 2013, 34, 451-459.

45. Bilc, D. I.; Orlando, R.; Shaltaf, R.; Rignanese, G.-M.; Íñiguez, J.; Ghosez. Hybrid Exchange-Correlation Functional for Accurate Prediction of the Electronic and Structural Properties of Ferroelectric Oxides Ph. Phys. Rev. B 2008, 77, 16510.

46. Bredow, T.; Gerson, A. Effect of Exchange and Correlation on Bulk Properties of MgO, $\mathrm{NiO}$, and CoO Phys. Rev. B 2000, 61, 5194-5201.

47. Kresse, G.; Hafner,J. Ab Initio Molecular Dynamics for Liquid Metals. Phys. Rev. B $1993,47,558$.

48. Kresse, G.; Hafner,j. Ab Initio Molecular-Dynamics Simulation of the Liquid-MetalAmorphous-Semiconductor Transition in Germanium. Phys. Rev. B 1994, 49, 14251.

49. Kresse, G.; Furthmüller. Efficiency of Ab-Initio Total Energy Calculations for Metals and Semiconductors Using a Plane-Wave Basis Set. J. Comput. Mat. Sci. 1996, 6, 15.

50. Kresse, G.; Furthmüller. Efficient Iterative Schemes for $A b$ Initio Total-Energy Calculations Using a Plane-Wave Basis Set. Phys. Rev. B 1996, 54, 11169. 
51. Blöchl, P. E. Projector Augmented-Wave Method. Phys. Rev. B 1994, 50, 1795317979.

52. Kresse, G.; Joubert. From Ultrasoft Pseudopotentials to the Projector AugmentedWave Method. D. Phys. Rev. 1999, 59, 1758-1775.

53. VASP

Potentials:

https://cms.mpi.univie.ac.at/vasp/vasp/Recommended PAW potentials DFT calc ulations using vasp 5 2.html access 6 February 2018

54. Schimka, L; Harl, J.; Kresse, G. J. Improved Hybrid Functional for Solids: The HSEsol Functional. Chem. Phys. 2011, 134, 024116-11.

55. Monkhorst, H. J.; Pack, J. D. Special Points for Brillouin-Zone Integrations. Phys. Rev. B 1976, 13, 5188-5192.

56. Aramburu, J. A.; Garcia-Lastra, J. M.; Garcia-Fernandez, P.; Barriuso, M. T.; Moreno, M. $\mathrm{Cu}^{2+}$ in Layered Compounds: Origin of the Compressed Geometry in the Model System $\mathrm{K}_{2} \mathrm{ZnF}_{4}: \mathrm{Cu}^{2+}$. Inorg.Chem. 2013, 52, 6923-6933.

57. Garcia-Lastra, J. M.; Aramburu, J. A.; Barriuso, M. T.; Moreno, M. Optical Properties of $\mathrm{Cr}^{3+}$-Doped Oxides: Different Behavior of Two Centers in Alexandrite. Phys. Rev. B 2006, 74, 115118.

58. Tosi, M. P. Cohesion of Ionic Solids in the Born Model. Solid State Phys.-Adv. Res. Appl. 1964, 16, 1-120.

59. van Gool, W.; Piken, A. G. Lattice Self-Potentials and Madelung Constants for Some Compounds. J. Mat. Science 1969, 4, 95-104

60. Witteveen, B. T.; Jongejan, O. L.; Brandwijk, V. Preparation of Compounds $\mathrm{A}_{2} \mathrm{CuCl}_{4-}$ ${ }_{x} \mathrm{Br}_{x}\left(\mathrm{~A}=\mathrm{K}, \mathrm{Rb}, \mathrm{NH}_{4}, \mathrm{Tl} ; \mathrm{x}=0,1,2\right)$ and Crystal Structures of Compounos $\mathrm{Rb}_{2} \mathrm{CuCl}_{4-x} \mathrm{Br}_{\mathrm{x}}$ with Ordered Distribution of the Anions. Mat. Res. Bull. 1974, 9, 345-352.

61. Chapuis, G.; Arend, H.; Kind, R. X-Ray Study of the Structural First-Order Phase Transition (Cmca-P4/ncm) in $\left(\mathrm{CH}_{3} \mathrm{NH}_{3}\right)_{2} \mathrm{CdCl}_{4}$. Phys. Stat. Sol. 1975, 31, 449-454.

62. Chapuis, G.; Kind, R.; Arend, H. X-Ray Study of Structural Phase Transitions in the Perovskite-Type Layer Compound $\left(\mathrm{CH}_{3} \mathrm{NH}_{3}\right)_{2} \mathrm{CdCl}_{4}$. Phys. Stat. Sol a 1976, 36, 285295.

63. Garcia-Lastra, J. M.; Aramburu, J. A.; Barriuso, M. T.; Moreno, M. Impurities in Noncubic Crystals: Stabilization Mechanisms for Jahn-Teller lons in Layered Perovskites. Phys. Rev. Lett. 2004, 93, 226402.

64. Aramburu, J. A.; García-Fernández, P.; J García-Lastra, J. M.; Moreno, M. Large Differences in the Optical Spectrum Associated with the Same Complex: The Effect of the Anisotropy of the Embedding Lattice. Inorg. Chem. 2017, 56, 8944-8953.

65. Aramburu, J. A.; Moreno, M. Bonding in $d^{9}$ Complexes Derived from EPR: Application to $\mathrm{CuCl}_{4}{ }^{2-}, \mathrm{CuBr}_{4}{ }^{2-}$, and $\mathrm{CdCl}_{2}: \mathrm{Cu}^{2+}$. J. Chem.Phys. 1985, 83, 6071-6083.

66. Bersuker, I. B. Pseudo-Jahn-Teller Effect-A Two-State Paradigm in Formation, Deformation, and Transformation of Molecular Systems and Solids, Chem. Rev. 2013, 113, 1351-1390.

67. Garcia-Lastra, J. M.; Barriuso, M. T.; Aramburu, J. A.; Moreno, M. Forces due to Changes of Electronic Density: a Complementary View of the Jahn-Teller Effect. Chem. Phys. 2005, 317, 103-110. 
68. Abragam, A.; Bleaney, B. Electron Paramagnetic Resonance of Transition ions, Clarendon Press, Oxford, 1970.

69. Garcia-Fernandez, P.; Garcia-Lastra, J. M.; Trueba, A.; Barriuso,M. T.; Aramburu, J. A.; Moreno, M. Insulators Containing $\mathrm{CuCl}_{4} \mathrm{X}_{2}{ }^{2-}\left(\mathrm{X}=\mathrm{H}_{2} \mathrm{O}, \mathrm{NH}_{3}\right)$ Units: Origin of the Orthorhombic Distortion Observed only for $\mathrm{CuCl}_{4}\left(\mathrm{H}_{2} \mathrm{O}\right)_{2}{ }^{2-}$. Phys. Rev. B 2012, 85, 094110.

70. Hagen, S. H.; Trappeniers, N. J. ESR of Copper Complexes in $\mathrm{NH}_{4} \mathrm{Cl}, \mathrm{ND}_{4} \mathrm{Cl}$ and $\mathrm{CsCl}$. Physica 1970, 47, 165-181.

71. Boettcher, F.; Spaeth, J. M. ENDOR Investigation of $\mathrm{Cu}^{2+}$ Centres in $\mathrm{NH}_{4} \mathrm{Cl}$. Phys. Stat. Sol. $b$ 1974, 61, 465-473.

72. Riley, M.; Hitchman, M. A.; Reinen, D.; Steffen, S. Temperature Dependence of the EPR Spectra of the Centers $\mathrm{Cu}\left(\mathrm{H}_{2} \mathrm{O}\right)_{2} \mathrm{Cl}_{4}{ }^{2-}, \mathrm{Cu}\left(\mathrm{N} \mathrm{H}_{3}\right)_{2} \mathrm{Cl}_{4}{ }^{2-}$ and $\mathrm{Cu}\left(\mathrm{H}_{2} \mathrm{O}\right)\left(\mathrm{N} \mathrm{H}_{3}\right) \mathrm{Cl}_{4}{ }^{2-}$ in $\mathrm{Cu}^{2+}$-Doped $\mathrm{N} \mathrm{H}_{4} \mathrm{Cl}$ : An Interpretation Using a Model of Dynamic Vibronic Coupling. Inorg. Chem. 1988, 27, 1924-1934.

73. Halvorson, K. E.; Patyel, B.; Willett, R. G. The Structure and EPR Properties of $\left(\mathrm{CH}_{2} \mathrm{OHCH}_{2} \mathrm{NH}_{3}\right)_{2} \mathrm{CuCl}_{4}$. J. Chem. Crystall. 1995, 25, 537-542

74. Furlani, C.; Sgamellotti, A.; Magrini, F.; Cordischi, D. ESR and Optical Spectrum of $\left(\mathrm{CH}_{3} \mathrm{NH}_{3}\right)_{2} \mathrm{CuCl}_{4}$. J. Mol. Spectr. 1967, 24, 270-276.

75. Wong, R. J. H.; Willett, R. D.; Drumheller, J. E. An EPR Study of Interlayer Exchange Coupling in the Quasi Two-Dimensional Salts, $\left\{\mathrm{C}_{n} \mathrm{H}_{2 n+1} \mathrm{NH}_{3}\right)_{2} \mathrm{CuCl}_{4}$ with $\mathrm{n}=1,2$, and 3. J. Chem. Phys. 1981, 74, 6018-6021.

76. Minner, E.; Lovy, D.; Bill, H. Electron-Paramagnetic-Resonance and Relaxation Study of Copper(II) and Silver(II) In $\mathrm{CsCdF}_{3}$ Single-Crystals. J. Chem. Phys. 1993, 99, 6378-6383.

77. Garcia-Fernandez, P.; Trueba, A.; Barriuso, M. T.; Aramburu, J.A.; Moreno, M. Tunneling Splitting of Jahn-Teller lons in Oxides. Phys. Rev. Lett. 2010, 104, 035901.

78. Garcia-Fernandez, P.; Aramburu, J.A.; Moreno, M.; Zlatar, M.; Gruden-Pavlovic, M. A Practical Computational Approach to Study Molecular Instability Using the Pseudo Jahn-Teller Effect. J. Chem. Theory. Comput. 2014, 10, 1824-1833.

79. Garcia-Fernandez, P.; Moreno, M.; Aramburu, J. A. Origin of the Exotic Blue Color of Copper-Containing Historical Pigments. Inorg. Chem. 2015, 54, 192-199.

80. Singh, S. K.; Eng, J.; Atanasov, M.; Neese, F. Covalency and Chemical Bonding in Transition Metal Complexes: An Ab Initio Based Ligand Field Perspective. Coord. Chem. Rev. 2017, 344, 2-25.

81. Low, W.; Suss, J. T. Jahn-Teller Effect of $\mathrm{Ni}^{+}$and $\mathrm{Cu}^{2+}$ in Single Crystals of Calcium Oxide. Phys. Lett. 1963, 7, 310-312.

82. Aramburu, J. A.; Garcia-Fernandez, P.; Garcia-Lastra, J. M.; Moreno, M. A Genuine Jahn-Teller System with Compressed Geometry and Quantum Effects Originating from Zero-Point Motion. ChemPhysChem 2016, 17, 2146-2156.

83. Grochala, W. Small Changes, Big Consequences. Nature Materials 2006, 5, 513-514

84. Kurzydłowski, D; Derzsi M; Mazejc, Z and Grochala W. Crystal, electronic, and magnetic structures of $\mathrm{M}_{2} \mathrm{AgF}_{4}(\mathrm{M}=\mathrm{Na}-\mathrm{Cs})$ phases as viewed from the $D F T+U$ method. Dalton Trans., 2016, 45, 16255-16261 
85. Kurzydłowski, D; Jaroń, T; Ozarowski, A; Hill, S; Jagličić, Z; Filinchuk, Y; Mazejc, Z and Grochala W. Local and Cooperative Jahn-Teller Effect and Resultant Magnetic Properties of $\mathrm{M}_{2} \mathrm{AgF}_{4}$ ( $\mathrm{M}=\mathrm{Na}-\mathrm{Cs}$ ) Phases. Inorg. Chem. 2016, 55, 11479-11489

86. Kugel, K. I.; Khomskii, D. I. The Jahn-Teller Effect and Magnetism: Transition Metal Compounds. Sov. Phys. Usp. 1982, 25, 231-256.

87. Desjardins, S. R.; Penfield, K. W.; Cohen, S. L.; Musselman, R. L.; Solomon, E. I. Detailed Absorption, Reflectance and UV Photoelectron Spectroscopic and Theoretical Studies of the Charge- Transfer Transitions of CuCl4 2-: Correlation of the Square-Planar and Tetrahedral Limits. J. Am. Chem. Soc. 1983, 105, 4590-4603.

88. Aramburu, J. A.; Moreno, M.; Bencini, A. Charge-Transfer Transitions in $\mathrm{CuCl}_{4}{ }^{2-}$ and $\mathrm{CuBr}_{4}{ }^{2-}$ Complexes: Dependence on the Metal-Ligand Distance. Chem. Phys. Lett. 1987, 140, 462-467.

89. Moreno, M.; Aramburu, J. A.; Barriuso, M. T. Electronic Properties and Bonding in Transition Metal Complexes: Influence of Pressure. Struct. Bonding 2004, 106, 127152. 


\begin{tabular}{|c|c|c|c|c|c|c|c|c|c|}
\hline System & Method & Group & a & $\mathrm{b}$ & C & $\beta$ & Rs & $\mathrm{R}_{\mathrm{L}}$ & $\mathrm{R}_{\mathrm{z}}$ \\
\hline \multirow[t]{4}{*}{$\left(\mathrm{CH}_{3} \mathrm{NH}_{3}\right)_{2} \mathrm{CuCl}_{4}$} & Experim. & $P 2_{1} / c$ & 9.814 & 7.424 & 7.155 & 70.8 & 2.287 & 2.902 & 2.312 \\
\hline & VASP & $P 2_{1} / C$ & 9.861 & 7.408 & 7.091 & 70.6 & 2.258 & 2.923 & 2.301 \\
\hline & CRYSTAL & $P 2_{1} / c$ & 10.294 & 7.070 & 7.130 & 65.8 & 2.299 & 2.747 & 2.314 \\
\hline & CRYSTAL & $P 2_{1} / c$ & - & - & - & 70.8 & 2.299 & 2.895 & 2.303 \\
\hline \multirow[t]{2}{*}{$\left(\mathrm{CH}_{3} \mathrm{NH}_{3}\right)_{2} \mathrm{CdCl}_{4}$} & Experim. & Cmca & 7.384 & 19.220 & 7.483 & 90.0 & 2.644 & 2.644 & 2.537 \\
\hline & CRYSTAL & Cmca & 7.502 & 19.148 & 7.437 & 90.0 & 2.671 & 2.671 & 2.591 \\
\hline \multirow[t]{3}{*}{$\mathrm{K}_{2} \mathrm{CuF}_{4}$} & Experim. & Cmca & 12.734 & 5.866 & 5.866 & 90.0 & 1.941 & 2.234 & 1.939 \\
\hline & CRYSTAL & Cmca & 12.734 & 5.824 & 5.824 & 90.0 & 1.900 & 2.223 & 1.937 \\
\hline & CRYSTAL & $14 / \mathrm{mmm}$ & 4.118 & 4.118 & 12.635 & 90.0 & 2.061 & 2.061 & 1.906 \\
\hline \multirow[t]{3}{*}{$\mathrm{Rb}_{2} \mathrm{CuCl}_{4}$} & Experim. & Cmca & 15.534 & 7.197 & 7.187 & 90.0 & 2.324 & 2.716 & 2.370 \\
\hline & CRYSTAL & Cmca & 15.743 & 7.155 & 7.156 & 90.0 & 2.316 & 2.744 & 2.380 \\
\hline & CRYSTAL & $14 / \mathrm{mmm}$ & 7.135 & 7.135 & 15.645 & 90.0 & 2.523 & 2.523 & 2.342 \\
\hline
\end{tabular}

Table 1. Experimental values of lattice parameters $a, b, c, \beta$ and $\mathrm{Cu}^{2+}-\mathrm{X}^{-}$distances $\mathrm{R}_{\mathrm{s}}, \mathrm{R}_{\mathrm{L}}$, $\mathrm{R}$, for $\left(\mathrm{CH}_{3} \mathrm{NH}_{3}\right)_{2} \mathrm{CuCl}_{4}$ (monoclinic $P 2_{1} / C$ space group, see Fig. 1) ${ }^{17},\left(\mathrm{CH}_{3} \mathrm{NH}_{3}\right)_{2} \mathrm{CdCl}_{4}$ (orthorhombic $\mathrm{Cmca}$ standard group, see Fig. 6) ${ }^{61,62}, \mathrm{~K}_{2} \mathrm{CuF}_{4}$ (orthorhombic Cmca standard group, see Fig. 2) ${ }^{34}$ and $\mathrm{Rb}_{2} \mathrm{CuCl}_{4}{ }^{60}$ compounds (orthorhombic Cmca standard group, see Fig. 3), compared to those optimized through first principle calculations using either VASP and CRYSTAL codes. Optimized results corresponding to a parent high symmetry tetragonal $14 / \mathrm{mmm}$ phase are also given for $\mathrm{K}_{2} \mathrm{CuF}_{4}$ and $\mathrm{Rb}_{2} \mathrm{CuCl}_{4}$ (note that in $\mathrm{Cmca}$ phase a is the long axis, but in $14 / \mathrm{mmm}$ is $\mathrm{C}$ ). The second CRYSTAL results for $\left(\mathrm{CH}_{3} \mathrm{NH}_{3}\right)_{2} \mathrm{CuCl}_{4}$ correspond to a calculation where the lattice parameters were fixed at the experimental values and thus only the three $\mathrm{Cu}^{2+}-\mathrm{Cl}^{-}$distances were derived through the minimization procedure. All distances are given in $\AA$ and angle $\beta$ in degrees.

\begin{tabular}{cccccccc}
\hline Pressure & $\mathrm{a}$ & $\mathrm{b}$ & $\mathrm{c}$ & $\beta$ & $\mathrm{Rs}$ & $\mathrm{R}_{\mathrm{L}}$ & $\mathrm{R}_{\mathrm{Z}}$ \\
\hline 0 & 9.861 & 7.408 & 7.091 & 70.59 & 2.258 & 2.923 & 2.301 \\
5 & 9.198 & 6.720 & 6.615 & 71.10 & 2.213 & 2.513 & 2.300 \\
10 & 9.120 & 6.454 & 6.385 & 71.45 & 2.166 & 2.376 & 2.306 \\
15 & 8.979 & 6.265 & 6.239 & 71.59 & 2.130 & 2.294 & 2.303 \\
20 & 8.937 & 6.124 & 6.111 & 71.18 & 2.096 & 2.230 & 2.313 \\
\hline
\end{tabular}

Table 2. Optimized values of the lattice parameters and $\mathrm{Cu}^{2+}{ }_{-} \mathrm{Cl}^{-}$distances obtained with the VASP code for $\left(\mathrm{CH}_{3} \mathrm{NH}_{3}\right)_{2} \mathrm{CuCl}_{4}$ under a hydrostatic pressure. All distances are given in $\AA$ and angle $\beta$ in degrees. The pressure unit is GPa. 


\begin{tabular}{lccccc}
\hline \multicolumn{1}{c}{ Compound } & $\mathrm{Rs}$ & $\mathrm{R}$ & $\mathrm{Rz}$ & $g_{\mathrm{z}}$ & Ref. \\
\hline$\left(\mathrm{HOCH}_{2} \mathrm{CH}_{2} \mathrm{NH}_{3}\right)_{2} \mathrm{CuCl}_{4}$ & 2.288 & 3.010 & 2.274 & 2.04 & 73 \\
$\left(\mathrm{CH}_{3} \mathrm{NH}_{3}\right)_{2} \mathrm{CuCl}_{4}$ & 2.283 & 2.907 & 2.297 & 2.05 & $17,74,41$ \\
& 2.287 & 2.902 & 2.312 & & \\
$\left(\mathrm{C}_{2} \mathrm{H}_{5} \mathrm{NH}_{3}\right)_{2} \mathrm{CuCl}_{4}$ & 2.285 & 2.975 & 2.277 & 2.05 & 18,75 \\
& & & & & \\
$\left(\mathrm{C}_{3} \mathrm{H}_{7} \mathrm{NH}_{3}\right)_{2} \mathrm{CuCl}_{4}$ & 2.29 & 3.04 & 2.29 & & 19 \\
$\left(\mathrm{CH}_{3} \mathrm{NH}_{3}\right)_{2} \mathrm{CdCl}_{4}: \mathrm{Cu}^{2+}$ & 2.441 & 2.690 & 2.279 & 2.05 & 40,41 \\
\hline
\end{tabular}

Table 3. Values of the two in plane distances, $R_{S}$ and $R_{L}$, and the out-of-plane distance, $\mathrm{R}_{\mathrm{z}}$, (in $\AA$ ) measured for some layered $\mathrm{Cu}^{2+}$ compounds at room temperature. In the case of $\left(\mathrm{CH}_{3} \mathrm{NH}_{3}\right)_{2} \mathrm{CuCl}_{4}$ the $\mathrm{RS}_{\mathrm{S}}, \mathrm{R}_{\mathrm{L}}$ and $\mathrm{R}_{\mathrm{Z}}$ distances determined at $\mathrm{T}=100 \mathrm{~K}$ are shown in italics. For comparison, the distances calculated for $\left(\mathrm{CH}_{3} \mathrm{NH}_{3}\right)_{2} \mathrm{CdCl}_{4}: \mathrm{Cu}^{2+}$ in the present work are included together with the available experimental $\mathrm{g}_{z}$ values for the considered systems.

\begin{tabular}{cccc}
\hline Local Symmetry & $\mathrm{R}_{\mathrm{S}}$ & $\mathrm{R}_{\mathrm{L}}$ & $\mathrm{R}_{\mathrm{Z}}$ \\
\hline $\mathrm{D}_{4 \mathrm{~h}}$ & 2.560 & 2.560 & 2.257 \\
$\mathrm{D}_{2 \mathrm{~h}}$ & 2.441 & 2.690 & 2.279 \\
$D_{2 h}$ & 2.419 & 2.705 & 2.261 \\
\hline
\end{tabular}

Table 4. Values of equilibrium $\mathrm{Cu}^{2+}-\mathrm{Cl}^{-}$distances $\mathrm{R}_{\mathrm{x}}, \mathrm{R}_{\mathrm{y}}, \mathrm{R}_{\mathrm{z}}$ derived by means of CRYSTAL code for $\left(\mathrm{CH}_{3} \mathrm{NH}_{3}\right)_{2} \mathrm{CdCl}_{4}: \mathrm{Cu}^{2+}$ by means of a supercell involving 84 ions. In a first step the calculations have been carried out forcing a local tetragonal symmetry $\left(R_{S}=R_{L}\right)$ around $\mathrm{Cu}^{2+}$ such as it is found for the host cation $\mathrm{Cd}^{2+}$. In a second step the two in-plane distances, $R_{S}$ and $R_{L}$ and the out of plane distance, $R_{Z}$ have been taken as free parameters when minimizing the total energy. Note that under $D_{2 h}$ local symmetry there are two equivalent solutions as the long in-plane distance, $R_{L}$, can be along either $X^{\prime}$ or $Y^{\prime}$ directions in Fig. 6. Results obtained through the VASP code for the $D_{2 h}$ equilibrium geometry are also yielded in italics for comparison. All distances are given in $\AA$. 


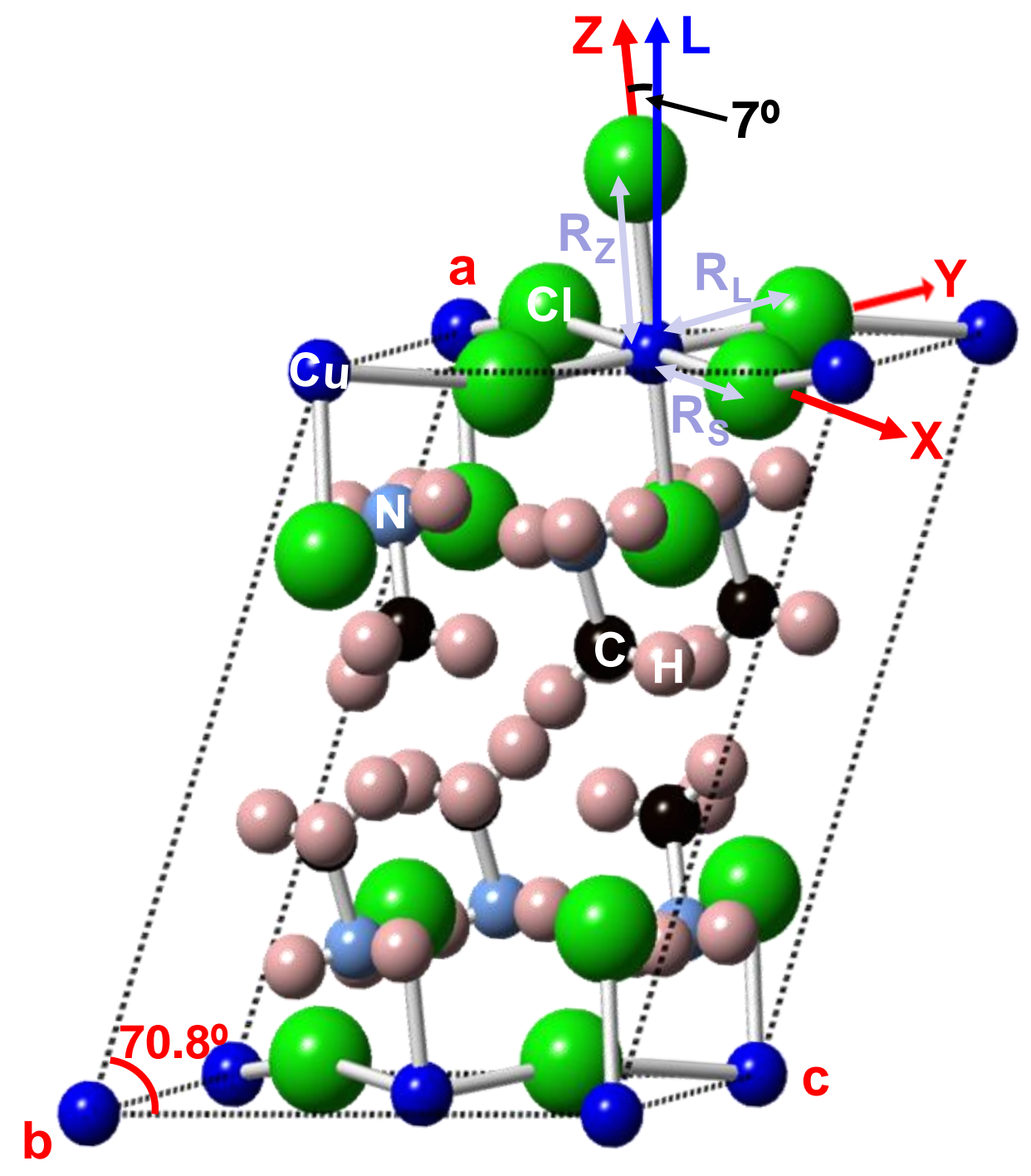

Figure 1. Layered perovskite structure of the hybrid organic-inorganic $\left(\mathrm{CH}_{3} \mathrm{NH}_{3}\right)_{2} \mathrm{CuCl}_{4}$ material with monoclinic standar $P 2_{1} / c$ space group. $\{X, Y, Z\}$ denote the local axes of a $\mathrm{CuCl}_{6}{ }^{4-}$ complex, with $\mathrm{X}$ the direction of the short in-plane $\mathrm{Cu}-\mathrm{Cl}$ distance, $\mathrm{R}_{\mathrm{s}}$, while $\mathrm{L}$ is a direction perpendicular to the inorganic $\mathrm{Cu}-\mathrm{Cl}$ layers. 

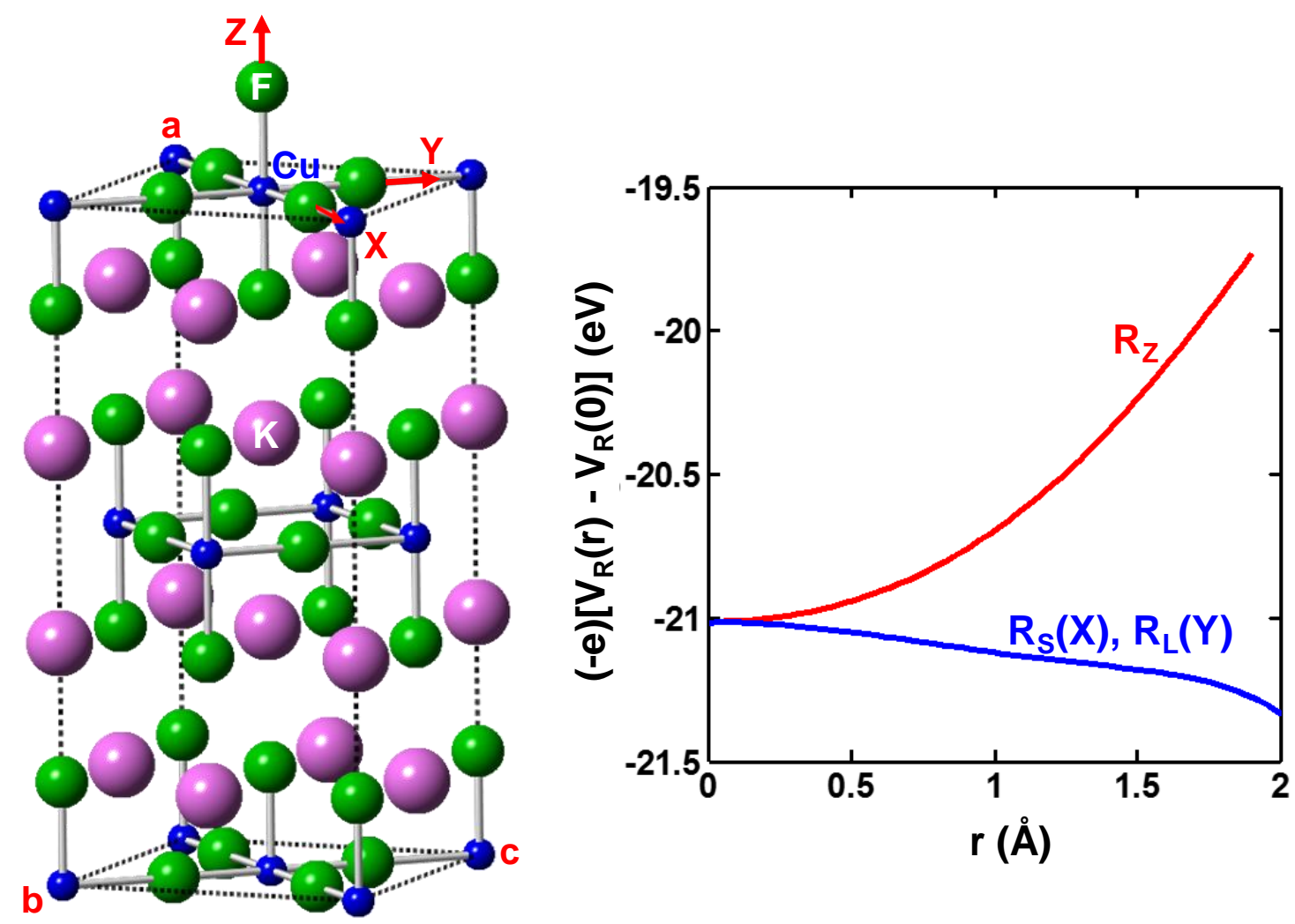

Figure 2. Left: Layered perovskite structure of the inorganic $\mathrm{K}_{2} \mathrm{CuF}_{4}$ material with orthorhombic standard Cmca space group. $\{\mathrm{X}, \mathrm{Y}, \mathrm{Z}\}$ denote the local axes of a $\mathrm{CuF}_{6}{ }^{4-}$ complex, with $X$ the direction of the short in-plane $\mathrm{Cu}-\mathrm{F}$ distance, Rs. Right: Potential energy $(-e) V_{R}(r)$ corresponding to the internal electric field created by the rest of lattice ions on a $\mathrm{CuF}_{6}{ }^{4-}$ complex depicted along the $\mathrm{X}, \mathrm{Y}$, and $\mathrm{Z}$ directions. 


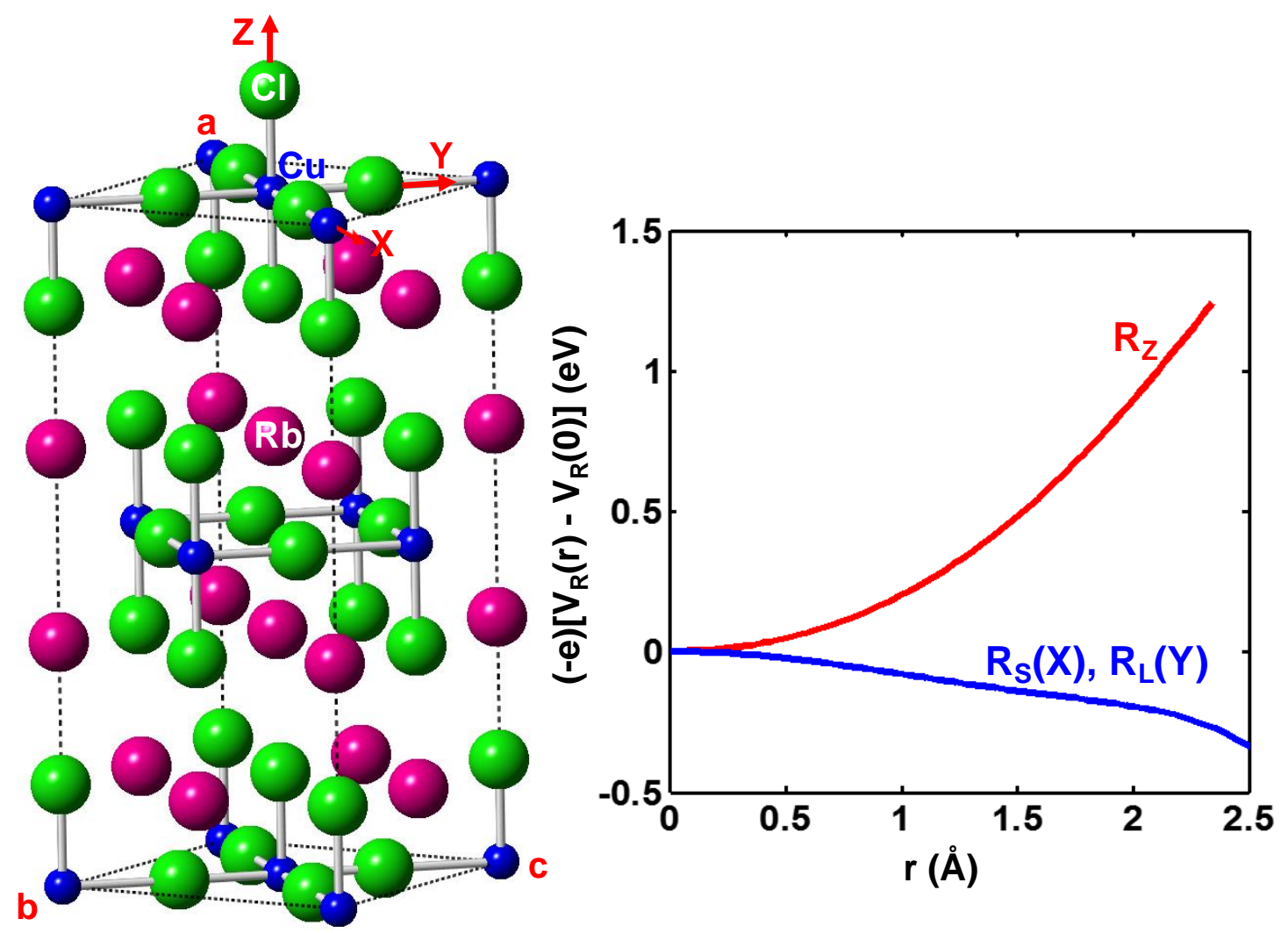

Figure 3. Left: Layered perovskite structure of the inorganic $\mathrm{Rb}_{2} \mathrm{CuCl}_{4}$ material with orthorhombic standard Cmca space group. $\{\mathrm{X}, \mathrm{Y}, \mathrm{Z}\}$ denote the local axes of a $\mathrm{CuCl}_{6}{ }^{4-}$ complex, with $\mathrm{X}$ the direction of the short in-plane $\mathrm{Cu}-\mathrm{Cl}$ distance, Rs. Right: Potential energy $(-e) V_{R}(r)$ corresponding to the internal electric field created by the rest of lattice ions on $\mathrm{CuCl}_{6}{ }^{4-}$ complex depicted along the $\mathrm{X}, \mathrm{Y}$, and $\mathrm{Z}$ directions. 


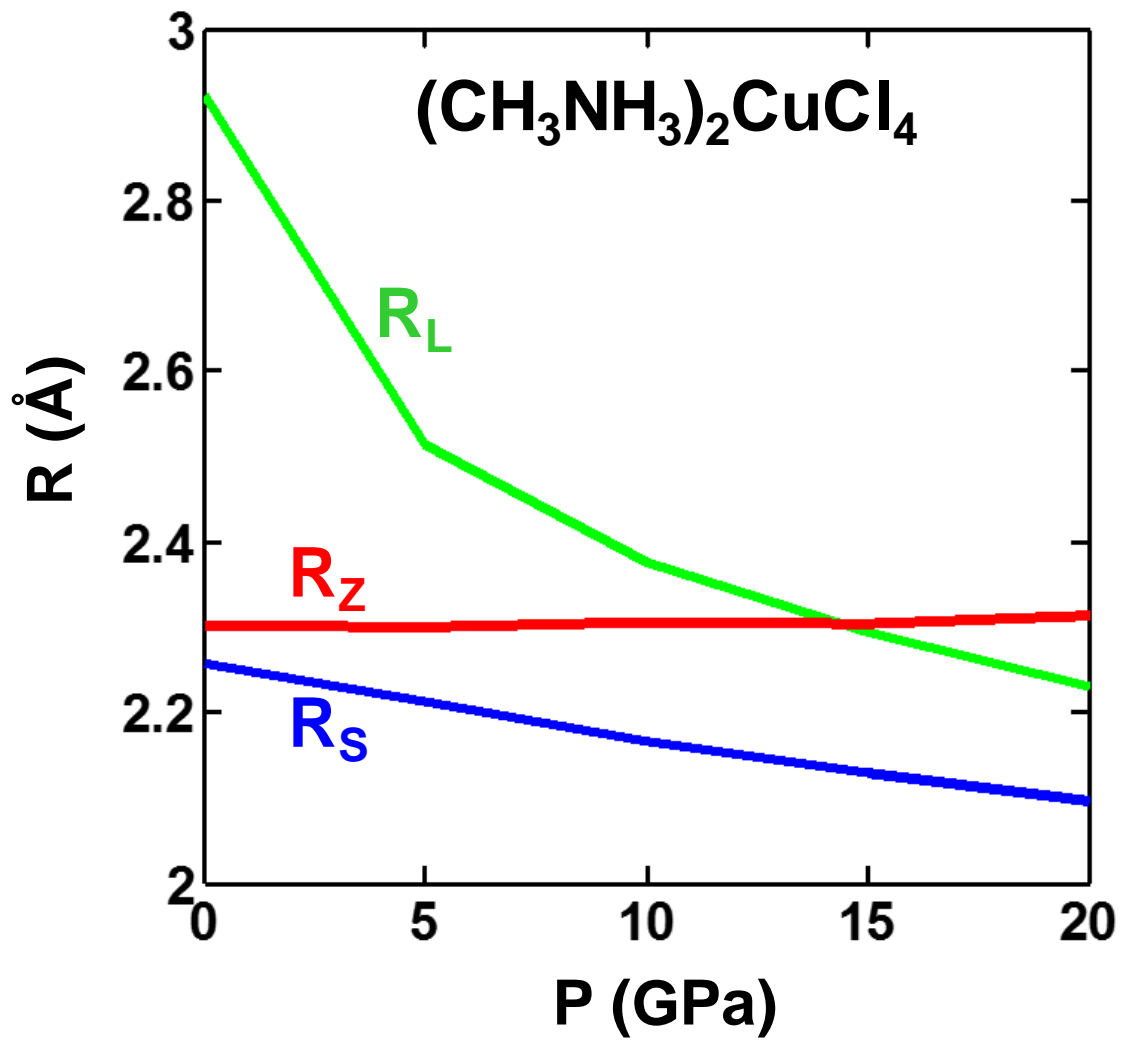

Figure 4. Variation with the pressure of the three copper-ligand distances in $\left(\mathrm{CH}_{3} \mathrm{NH}_{3}\right)_{2} \mathrm{CuCl}_{4}$ compound obtained from ab initio calculations. 

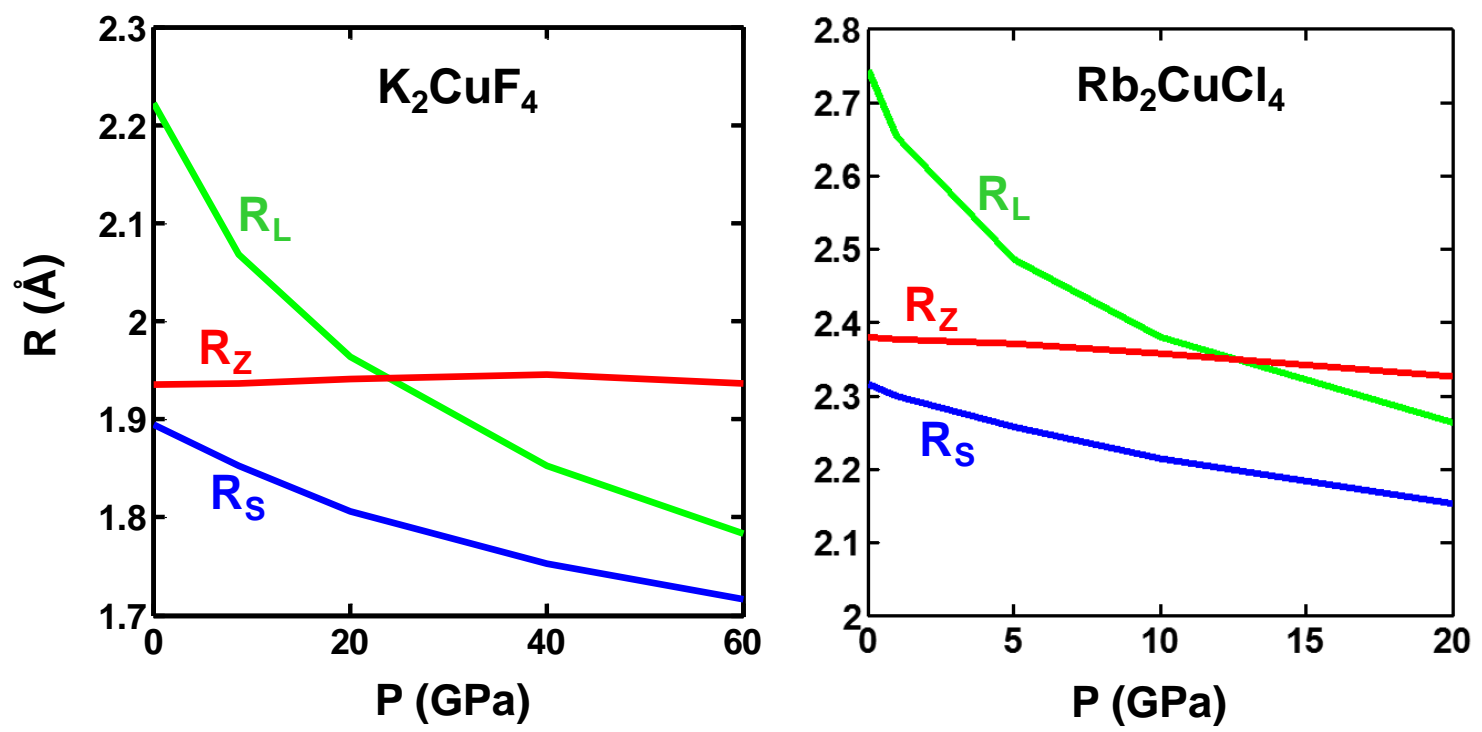

Figure 5. Variation with the pressure of the three copper-ligand distances in $\mathrm{K}_{2} \mathrm{CuF}_{4}$ and $\mathrm{Rb}_{2} \mathrm{CuCl}_{4}$ compounds obtained from ab initio calculations. 


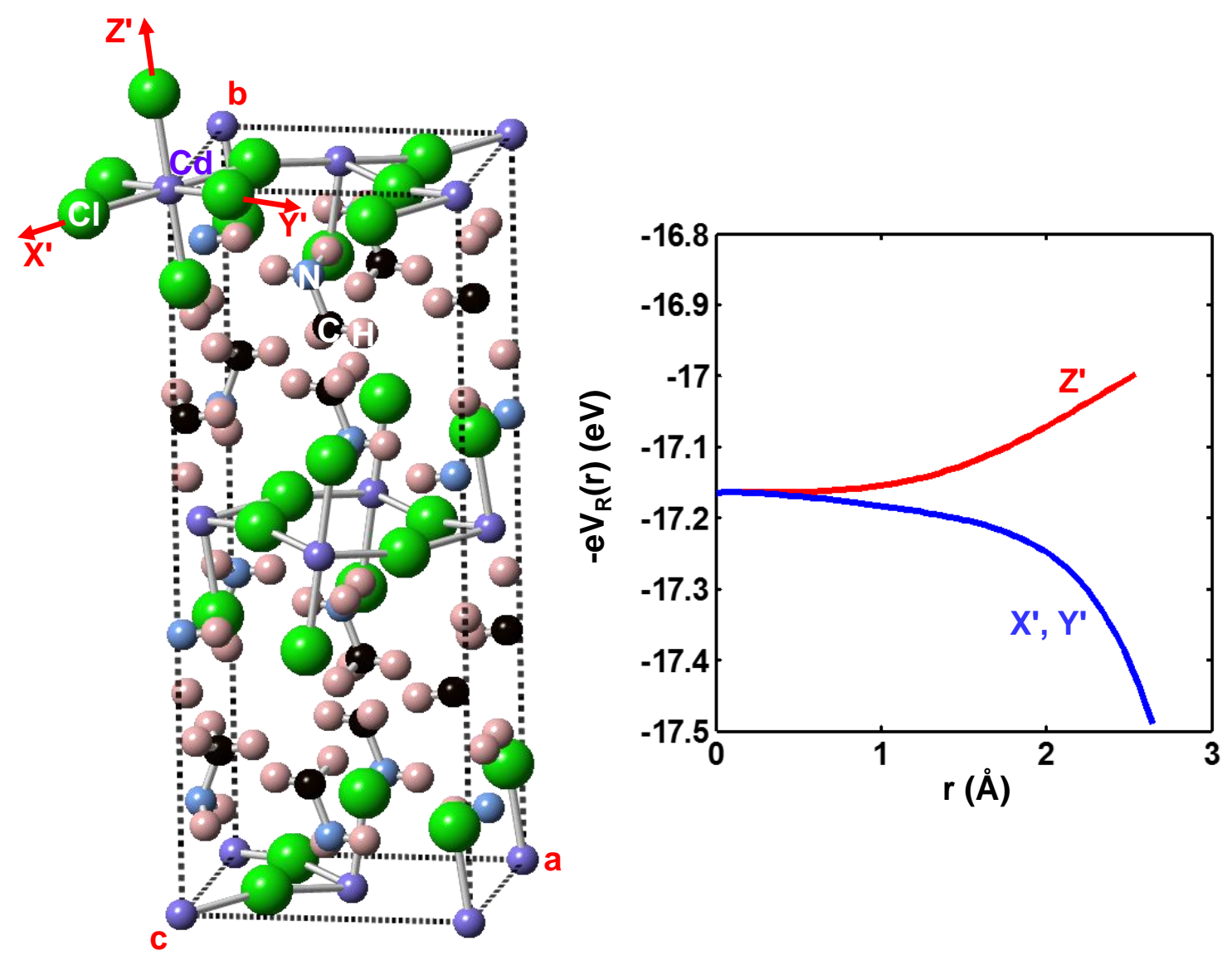

Figure 6. Left: Layered perovskite structure of the hybrid organic-inorganic $\left(\mathrm{CH}_{3} \mathrm{NH}_{3}\right)_{2} \mathrm{CdCl}_{4}$ material with orthorhombic standar $\mathrm{Cmca}$ space group. $\left\{\mathrm{X}^{\prime}, \mathrm{Y}^{\prime}, \mathrm{Z}^{\prime}\right\}$ denote the local axes of a tetragonal $\mathrm{CdCl}_{6}{ }^{4-}$ complex. Right: Potential energy $(-e) \mathrm{V}_{\mathrm{R}}(\mathbf{r})$ corresponding to the internal electric field created by the rest of lattice ions on a $\mathrm{CdCl}_{6}{ }^{4-}$ complex depicted along the $\mathrm{X}^{\prime}, \mathrm{Y}^{\prime}$, and $\mathrm{Z}^{\prime}$ directions. 


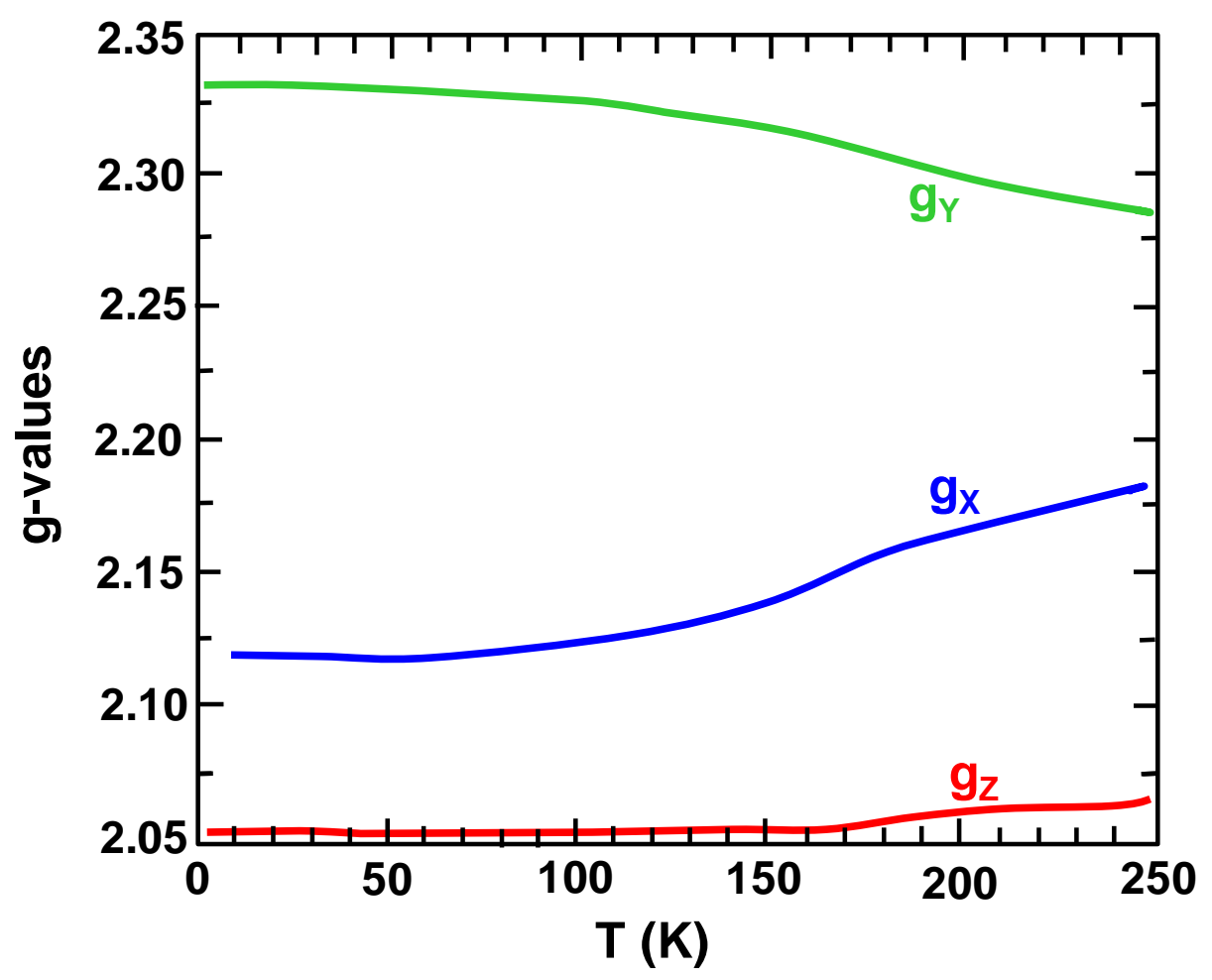

Figure 7. Experimental temperature dependence of the g-values of $\mathrm{Cu}^{2+}$-doped $\left(\mathrm{CH}_{3} \mathrm{NH}_{3}\right)_{2} \mathrm{CdCl}_{4}$. Adapted from Ref. ${ }^{38}$. 

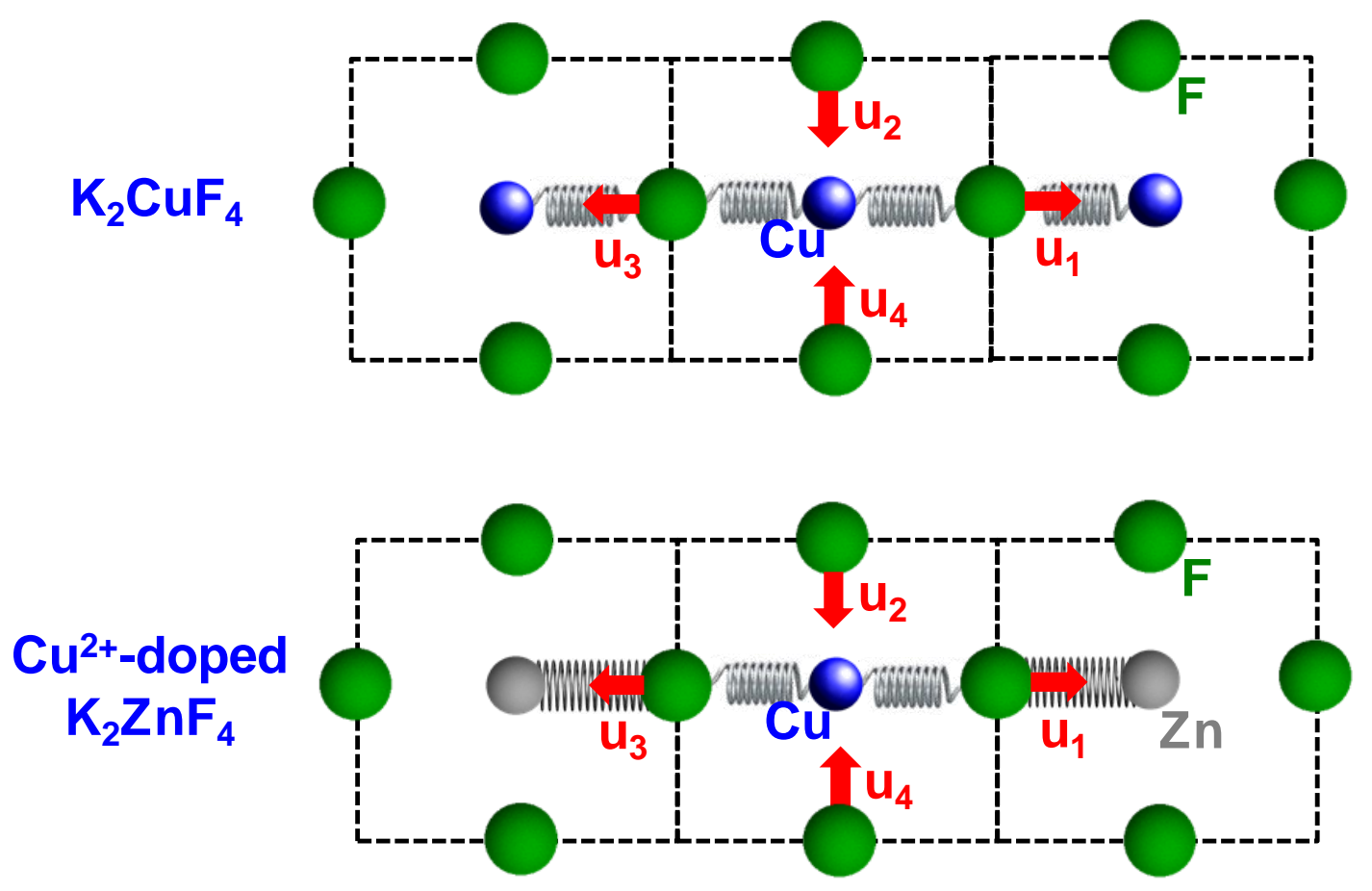

Figure 8. Simple scheme outlining the differences between the $\mathrm{B}_{1 \mathrm{~g}}$ non-symmetric mode in $\mathrm{K}_{2} \mathrm{CuF}_{4}$ pure compound and in $\mathrm{Cu}^{2+}$-doped $\mathrm{K}_{2} \mathrm{ZnF}_{4}$. Note that for $\mathrm{K}_{2} \mathrm{CuF}_{4}$ the motion of a ligand implies the activation of springs corresponding to two neighbors $\mathrm{Cu}^{2+}$ complexes. In the case of $\mathrm{K}_{2} \mathrm{ZnF}_{4}: \mathrm{Cu}^{2+}$ that motion involves the $\mathrm{Cu}^{2+}$ complex and also that of a neighbor $\mathrm{Zn}^{2+}$ complex. 
Table of Contents Graphic

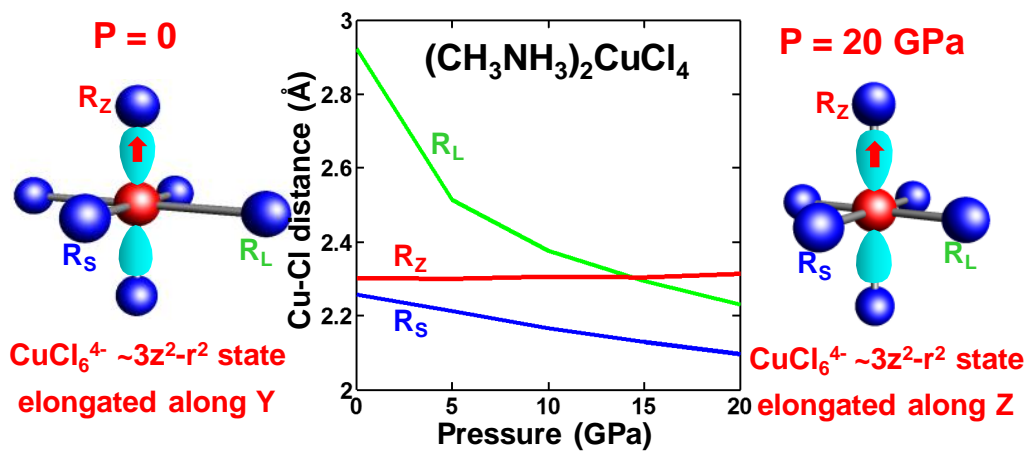

